Linköping studies in science and technology.

Dissertation, No. 1931

\title{
PERSPECTIVE CORRECT HAND-HELD AUGMENTED \\ REALITY FOR IMPROVED GRAPHICS AND INTERACTION
}

Ali Samini

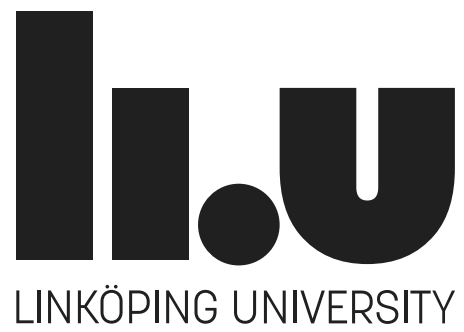

Division of Media and Information Technology

Department of Science and Technology

Linköping University, SE-601 74 Norrköping, Sweden

Norrköping, April 2018 
Perspective Correct Hand-held Augmented Reality for Improved Graphics and Interaction

Copyright (C) 2018 Ali Samini (unless otherwise noted)

Division of Media and Information Technology

Department of Science and Technology

Campus Norrköping, Linköping University

SE-601 74 Norrköping, Sweden

ISBN: 978-91-7685-317-7

ISSN: 0345-7524

Printed in Sweden by LiU-Tryck, Linköping, 2018 
Dedicated to my mother and father 



\section{Acknowledgments}

I would like to thank all the people that helped me during my research, making my Ph.D. studies enjoyable and memorable.

First, I like express my deep gratitude to my main supervisor, Karljohan Lundin Palmerius, for his research assistance, great discussions, and guidance through these years. You were always there when I needed help. I always felt lucky to have you as my supervisor and your vast knowledge, and passion for science inspired me a lot. Thank you so very much, KJ.

I would like to also express my gratitude towards, Anders Ynnerman, for giving me the opportunity to pursue my research in a wonderful scientific environment. A special thanks is due to Stefan Gustavson, for his great help, inspiring discussions, and for always thinking out of the box and making science much more fun. I want to thank Pierangelo Dell'Acqua, for his guidance and friendship through these years, Matthew Cooper, for his great help with proofreading my thesis, our administrators, Eva Skärblom and Gun-Britt Löfgren, for their help and support, Camilla Forsell and Niklas Rönnberg for their assist with statistical analysis, and the people involved with the CUAS project, for their help and assistance. I also would like to thank all my colleagues and friends for their help and support, specially Ehsan Miandji, Saghi Hajisharif, Mark E Dieckmann, Hootan Mohseni, Valaali Hamid, and Milad Mahdavian-your friendship made my research a delightful journey.

I devote my deepest gratitude to my family, without you this would have not been possible. My father, who always inspired me to go towards my dreams and stood behind me. My mother, who made the huge sacrifice for being far from his son for many years, and my sis who encouraged me through my research and many times mentioned that she does not want a brother without a Ph.D.!

$\diamond$

This work has been partly financed by the Swedish Foundation for Strategic Research (SSF). 



\section{Abstract}

With Augmented Reality, also termed AR, a view of the real world is augmented by superimposing computer-generated graphics, thereby enriching or enhancing the perception of the reality. Today, lots of applications benefit from AR in different areas, such as education, medicine, navigation, construction, gaming, and multiple other areas, using primarily head-mounted AR displays and AR on hand-held tablets and smart phones. Tablets and phones are highly suitable for AR, as they are equipped with high resolution screens, good cameras and powerful processing units, while being readily available to both industry and home use. They are used with video see-through $\mathrm{AR}$, were the live view of the world is captured by a camera in real time and subsequently presented together with the computer graphics on the display.

In this thesis I put forth our recent work on improving video see-through Augmented Reality graphics and interaction for hand-held devices by applying and utilizing user perspective. On the rendering side, we introduce a geometry-based user perspective rending method aiming to align the on screen content with the real view of the world visible around the screen. Furthermore, we introduce a device calibration system to compensate for misalignment between system parts. On the interaction side we introduce two wand-like direct 3D pose manipulation techniques based on this user perspective. We also modified a selection technique and introduced a new one suitable to be used with our introduced manipulation techniques.

Finally, I present several formal user studies, evaluating the introduced techniques and comparing them with concurrent state-of-the-art alternatives. 



\section{Populärvetenskaplig Sammanfattning}

I förstärkt verklighet, även kallat AR från engelskans Augmented Reality, förstärks en vy av verkligheten genom att den överlagras med datorgenererad grafik, vilket kan ge nytta inom många olika områden såsom utbildning, medicin, navigation, konstruktion och spel. De vanligaste teknikerna för detta är AR-glasögon samt AR på handhållna surfplattor och telefoner. Handhållna enheter är väl lämpade för AR, eftersom de ofta är utrustade med högupplösta skärmar, bra kameror och kraftfulla processorer, samtidigt som de är lättillgängliga för både industri och hemmabruk. På dessa används video-baserad $\mathrm{AR}$, där verkligheten fångas med en kamera i realtid för att sedan presenteras tillsammans med datorgrafik på skärmen. När förstärkningen skapas på en skärm man håller i handen uppstår utmaningar både i form av presentation av innehåll och interaktion med det som visas - hur skapar man en naturlig koppling mellan skärmens rymd och världen omkring oss?

Det vanligaste sättet att implementera video-baserad AR är genom att visa kamerans vy som den är och anpassa datorgrafiken efter den, vilket leder till att det som syns på skärmen inte hamnar rätt i förhållande till vad som syns runt skärmen och att vyn styrs av åt vilket håll man riktar enheten med dess kamera. Vi föreslår därför att man korrigerar perspektivet med hjälp av geometrisk projektion så att både kamerans vy och datorgrafiken justeras och anpassas till verkligheten utifrån användarens synvinkel. Effektiviteten hos den här tekniken demonstreras genom en fungerande prototyp. Vi presenterar också en teknik för att kalibrera systemet och kompensera för placeringen av kamera, skärm och enhetens pose-detektering.

Interaktion med virtuella objekt i handhållen AR görs vanligen med hjälp av pekskärmen genom fingerberöring och gester. Grundproblemet med dessa tekniker är avsaknaden av direkt 3D-kontroll (x, y, z-position samt rotation) när man bara har två dimensioner i input (x,y-position på skärmen). En lösning som möjliggör full kontroll i 3D är att koppla rörelser hos den handhållna enheten till rörelser hos det virtuella objektet, på samma sätt som handkontroller används i VR. Ett problem är att när man roterar på surfplattan för att rotera ett objekt så roteras också vyn. Detta gör att objektet kan hamna utanför vyn eller att objektet flyttas, beroende på vilken typ av mappning man väljer. Vi föreslår att man använder korrigerat perspektiv för att komma runt detta, så att vyn inte påverkas av interaktionen. Det har visat sig i våra studier att det finns en sätt att mappa rörelse till manipulation i korrigerat perspektiv som är både intuitiv och naturlig. Vi kompletterar även manipulationen med olika förslag på hur man effektivt kan välja vilket objekt man vill manipulera mellan flera objekt i en scen.

Vi har genomfört fem användarstudier för att analysera och jämföra beteende och prestanda hos de föreslagna teknikerna. Två studier utfördes för att undersöka effekten av korrigerat perspektiv på interaktion genom pekskärmen, både för sökhitta-klicka och för manipulation. Korrigerat perspektiv visade sig vara till nackdel 
i sökuppgifter, men användarna föredrog detta perspektiv för att välja objekt. För pose-manipulation ansåg försökspersonerna korrigerat perspektiv vara mer naturligt och intuitivt, men det resulterade inte i statistiskt säkerställd prestandaökning.

En annan studie genomfördes för att undersöka effekten av vyns perspektiv på posemanipulation när enhetens rörelse användes som input. Här jämfördes manipulation i korrigerat perspektiv med två metoder för manipulation i kamerans perspektiv i två olika situationer. I den första situationen är objektet nära användaren, så att det är möjligt att röra sig runt objektet. Det resulterade i statistiskt signifikant bättre prestanda med korrigerat perspektiv jämfört med ett av de etablerade alternativen, men våra data bekräftade inte bättre prestanda jämfört med det andra. I den andra situationen är föremålet istället långt bort. I denna situation var manipulation i korrigerat perspektiv statistiskt signifikant snabbare.

I en sista studie jämförde vi olika tekniker för val av objekt samt olika sätt att koppla rörelse till manipulation i korrigerat perspektiv. Resultaten visar att urval med hjälp av ikoner på skärmen är långsammare än både val genom klicka på objektet och genom att sikta med den handhållna enheten. Att klicka på objektet för urval uppfattades som uttröttande, men uppskattades ändå som teknik. När det gäller manipulering pekar resultaten från studien tydligt på fördelarna med en teknik där objektet, när valt, flyttas tillsammans med varje förändring av vyn. Försökspersonernas preferenser stämmer överens med de statistiska resultaten och visar att det var lätt att lära sig och använda, mindre uttröttande och mer naturligt och intuitivt än alternativen.

Vi drar slutsatsen att korrigerat perspektiv möjliggör visualisering i AR som är anpassad till verkligheten utifrån användarens synvinkel och att vår föreslagna teknik är en fullgod lösning för detta, vilket resulterar i en handhållen enhet som fungerar som ett fönster in i en förstärkt verklighet. Vi har dock sett att korrigerat perspektiv inte alltid är att föredra men att det uppfattas som naturligt och intuitivt medan det samtidigt möjliggör mer effektiva metaforer för val av objekt och pose-manipulering. Således går det att använda enhetens rörelser som input i AR-interaktion mer effektivt än att använda gester på pekskärmen. Att perspektivet är bestämt utifrån användaren motverkar att rotation av enheten påverkar vyn under tiden manipulering pågår och möjliggör därmed att användaren kontinuerligt arbetar med objektet utan att det försvinner ur vyn. Vi fann också att valet av teknik kan vara extra viktigt beroende på hur nära man är det man vill manipulera. Sammantaget ger korrigerat perspektiv en naturlig och intuitiv visuell koppling från världen till dess representation på skärmen och det finns dessutom samtidigt en särskilt naturlig och intuitiv koppling tillbaka från rörelse till kontroll och styrning av virtuella objekt. 


\section{Publications}

The following publications are included in this dissertation:

Paper A: A. Samini and K. Lundin Palmerius. A perspective geometry approach to user-perspective rendering in hand-held video see-through augmented reality. In Proceedings of the 20th ACM Symposium on Virtual Reality Software and Technology, VRST '14, pages 207-208, New York, NY, USA, 2014. ACM

Paper B: A. Samini and K. Lundin Palmerius. Device registration for 3d geometrybased user-perspective rendering in hand-held video see-through augmented reality. In L. T. De Paolis and A. Mongelli, editors, Augmented and Virtual Reality, volume 9254 of Lecture Notes in Computer Science, pages 151-167. Springer International Publishing, 2015

Paper C: A. Samini and K. Lundin Palmerius. A User Study on Touch Interaction for User-Perspective Rendering in Hand-Held Video See-Through Augmented Reality, pages 304-317. Springer International Publishing, Cham, 2016

Paper D: A. Samini and K. Lundin Palmerius. A study on improving close and distant device movement pose manipulation for hand-held augmented reality. In Proceedings of the 22Nd ACM Conference on Virtual Reality Software and Technology, VRST '16, pages 121-128, New York, NY, USA, 2016. ACM

Paper E: A. Samini and K. L. Palmerius. Popular performance metrics for evaluation of interaction in virtual and augmented reality. In 2017 International Conference on Cyberworlds (CW), volume 00, pages 206209, 2017

Paper F: A. Samini and K. Lundin Palmerius. Towards the ultimate handheld augmented reality interaction | a study on selection and pose manipulation techniques. 2017

The following publication, is not included in the dissertation:

- P. Dell'Acqua, L. V. Klompstra, T. Jaarsma, and A. Samini. An assistive tool for monitoring physical activities in older adults. In 2013 IEEE 2nd International Conference on Serious Games and Applications for Health (SeGAH), pages 1-6, 2013 



\section{Contributions}

Paper A:

A perspective geometry approach to user-perspective rendering in handheld video see-through augmented reality

Paper B:

Device Registration for 3D Geometry-Based User-Perspective Rendering in Hand-Held Video See-Through Augmented Reality

Paper C:

A User Study on Touch Interaction for User-Perspective Rendering in Hand-Held Video See-Through Augmented Reality

Paper D:

A study on improving close and distant device movement pose manipulation for hand-held augmented reality

Paper E:

Popular Performance Metrics for Evaluation of Interaction in Virtual and Augmented Reality

Paper F:

Towards the Ultimate Hand-Held Augmented Reality Interaction - A Study on selection and pose manipulation techniques. Submitted to the Journal on Multimodal User Interfaces 



\section{Contents}

Acknowledgments

Abstract vii

Populärvetenskaplig Sammanfattning ix

List of publications $\quad$ xi

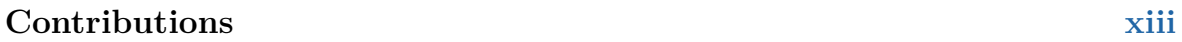

1 Introduction 1

1.1 Augmented Reality 2

1.2 Augmented Reality Display Systems 2

1.3 Hand-held Augmented Reality Perspectives 2

1.4 Hand-held Augmented Reality Interaction 3

1.5 Contributions 5

2 User Perspective Augmented Reality 7

2.1 Geometry-based User Perspective Rendering 8

2.1.1 Dynamic Virtual View 9

2.1.2 Real World View 10

2.1.3 Prototype and System Demonstration 12

2.1.4 Reality and Virtuality Alignment 13

2.2 System Calibration 16

$\begin{array}{lll}\text { 2.2.1 Camera Pose } & 17\end{array}$

$\begin{array}{lll}2.2 .2 & \text { Screen Pose } & 19\end{array}$

3 Device Pose-based Interaction 23

3.1 DPR Device Pose-based Manipulation 23

3.2 UPR Device Pose-based Manipulation 24

3.3 Device Pose-based Selection 28

3.3.1 Background 28

3.3.2 Modified Center Selection 29

$\begin{array}{lll}3.3 .3 & \text { Icons-based Selection } & 29\end{array}$

4 Formal User Evaluations 33

4.1 Popular Performance Metrics for Interaction 34

4.2 Perspective Effect on Multi-touch Interaction 35

4.2.1 Test Environment and Prototype 35

4.2.2 Participants and Pre-test Procedure 35 
4.2.3 Find-and-Select Study $\quad 36$

4.2.4 Pose Manipulation Study 39

4.3 Perspective Effect on Device Pose-based Manipulation 43

4.3.1 Expected Outcome and Hypotheses 43

4.3.2 Experimental Design 44

4.3.3 Test Environment and Prototype 44

4.3.4 Participants and Procedure 44

4.3.5 Results 45

4.3.6 Discussion 49

4.4 UPR Device-based Interaction Evaluation 50

4.4.1 Test Environment and Prototype 50

4.4.2 Participants and General Procedure $\quad 50$

4.4.3 Selection Study 51

4.4.4 Manipulation Study $\quad 55$

5 Concluding remarks $\quad 59$

5.1 User Perspective Augmented Reality $\quad 59$

5.2 Device Pose-based Interaction 60

$\begin{array}{ll}\text { Bibliography } & 65\end{array}$

$\begin{array}{ll}\text { Paper A } & 73\end{array}$

$\begin{array}{ll}\text { Paper B } & 79\end{array}$

$\begin{array}{ll}\text { Paper C } & 99\end{array}$

$\begin{array}{ll}\text { Paper D } & 117\end{array}$

$\begin{array}{lr}\text { Paper E } & 129\end{array}$

$\begin{array}{lr}\text { Paper F } & 137\end{array}$ 


\section{1}

\section{Introduction}

Today computers are able to create fully or partially immersive virtual environments. Such environments either fully replace the real world with computer-generated graphics, called Virtual Reality (VR), or blend the real and virtual worlds by superimposing computer-generated augmentations on the real world, called Augmented Reality (AR). There are various definitions for the characteristics of AR and VR environments; for example, Nielsen and Jakob suggest that virtual environments should replicate our interaction with the physical world to be readily accepted [31]. Bowman and Hodges, on the other hand, suggest that virtual environments should enhance the physical world to create possibilities which do not exist in the real world [8]. Milgram defined a continuum between the real and virtual environments by a reality-virtuality line [28], as illustrated in Figure 1.1. This line starts from the real environment, on the left, and goes towards the virtual environment based on how much of the environment is generated by computer graphics. While AR is placed closer to the real world and VR to the virtual world, both are considered to be subsets of a Mixed Reality (MR) environment.

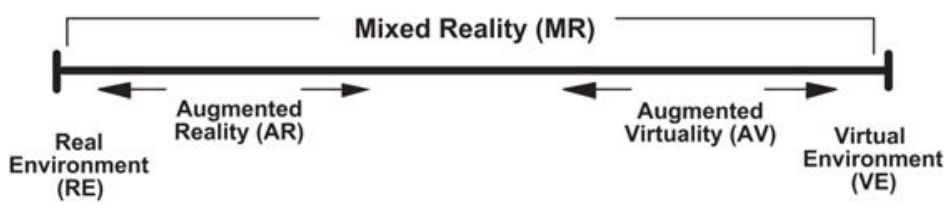

Figure 1.1: Milgram's reality-virtuality continuum, [28]. 


\subsection{Augmented Reality}

AR provides additional information about the real world, as graphical augmentations that the user cannot detect with their own senses, and so enhances a user's perception of and interaction with the real world [2]. AR was first introduced by Sutherland in 1960s [46], however it took several years before becoming a research and application area. Today lots of applications benefit from AR in different areas, such as education [15, 25, 49], medicine [3, 7, 42], navigation [22, 29], construction [24], and gaming [13, 34].

Based on the requirements of the different applications, there are various ways to create AR. In general, the necessary characteristics of AR, as defined by Azuma [2], are (1) a view of the real world with virtual information, such as text or computer graphics, (2) interactively, in real-time, and (3) co-registration of the virtual information with real objects so that they are aligned.

\subsection{Augmented Reality Display Systems}

Based on the technique used to merge the computer generated augmentations with the user's view of the real world, AR can be categorized into optical see-through, projective and video see-through. With optical see-through AR, the user is able to directly see the real world, while the augmentations are added to the view through a semi-transparent display. HoloLens from Microsoft, for instance, is a head-mounted display used for optical see-through AR (see Figure 1.2, center). In projective AR, projectors are used to directly project graphical augmentations onto real world objects. The Pool Live Aid project is an example of projective AR, where the expected trajectory of balls are projected on a pool table (see Figure 1.2, right). With video see-through $\mathrm{AR}$, a video camera (two cameras for stereo) is used to capture the view of the real world that is then digitally combined with the augmentations and displayed on an opaque screen. Hand-held portable screens, when equipped with a camera, can be used for video see-through AR. These devices, such as smart-phones and tablets, are popular today, to a level where they can almost be called ubiquitous. Furthermore, most of these devices are equipped with powerful processing units, high resolution screens and cameras, making them capable of video see-through AR. For instance, IKEA Place is an application for hand-held devices that uses video see-through AR to add virtual furnitures to a desired space (see Figure 1.2, left).

\subsection{Hand-held Augmented Reality Perspectives}

Different techniques are used to create hand-held video see-through AR, however they are usually created using the following pipeline: 


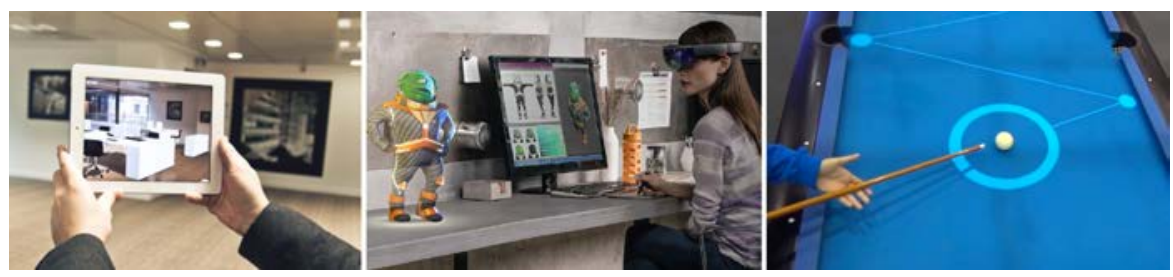

Figure 1.2: Augmented Reality displays. Left: IKEA Place mobile application is used on a tablet device to visualize furniture in an empty office space. Center: Artistic rendering by Microsoft of impressions of using a HoloLens for optical see-through AR where a 3D model is displayed in a real environment. Right: The Pool Live Aid project uses a projector to visualize the redirected path of a billiard ball on the table.

1. the real world view is captured by a camera which is fixed to the hand-held device,

2. the camera pose is estimated using a tracking method (see examples here [51]),

3. augmentations in the form of computer graphics, such as textual information or virtual objects, are overlaid and co-registered with their correspondence with the video feed based on the tracked pose of the camera, and

4. the combined AR view is displayed on the screen of the hand-held device.

This approach creates the view on the screen based completely on the view of the camera and so we can expect a certain misalignment, from the user's point of view, between what is rendered on the screen and the real world around the screen (see Figure 1.3, left). An alternative approach reduces the latter misalignment by creating an AR view based on the perspective of the user instead of the camera. As is illustrated in Figure 1.3 (right), This technique reduces the misalignment between what is rendered on the screen and what is visible from around it from the user's point of view. Creating a hand-held video see-through AR which aligns the AR graphics with the real world is one of the challenges that this thesis addresses, as presented in Chapter 2.

\subsection{Hand-held Augmented Reality Interaction}

An enabling factor for AR applications is the possibility to provide intuitive and efficient interaction. There are various ways to interact with a virtual environment in AR and VR applications. Bowman and Hodges [8] categorize interaction with a virtual environment into three task categories: viewpoint motion control, selection, and manipulation, all of which they call 'universal tasks'. Viewpoint motion control, also called navigation, commonly refers to moving the user's viewpoint through an 


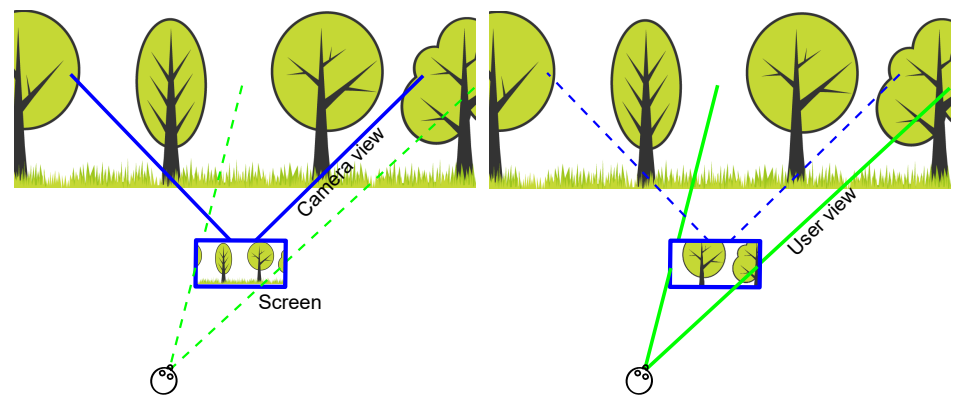

Figure 1.3: Video see-through AR on a tablet screen. Left: The common AR approach, where the view of the camera is used to create the AR view. Right: An alternate technique, where the user's view is used to create the AR view to reduce the misalignment between the on-screen graphics and the real world.

AR or VR environment. Selection refers to choosing a virtual object, which can be followed by manipulation: changing the object's position, orientation, or scale.

In hand-held $\mathrm{AR}$ viewpoint motion is usually performed by moving either the device or the user's head. With a touch-enabled hand-held device a single-touch on the screen is commonly used for selection while multi-touch gestures are used for manipulation. Some examples of multi-touch manipulation techniques are presented in [16], and [27].

Manipulating the third dimension is not directly available on a 2D screen and so the touch-based manipulation requires the introduction of metaphors in the form of $2 \mathrm{D}$ gestures. This mapping between 2D on-screen touch and 3D interaction lacks the direct 3D connection, which can primarily effect selecting, translating, and rotation of an object in depth. Furthermore, with touch-based interaction the fingers are placed between the user's view and the screen which may cause occlusion of visual feedbacks. Also, holding a device with one hand while performing the touch-based interaction with the other can lead to hand fatigue, especially for heavier devices such as tablets.

With head worn systems, direct 3D interaction is provided by using wands or mid-air gestures [20, 21] (see Figure 1.4, right). With hand-held devices, however, using a wand or mid-air gestures will force the user to hold the device with one hand and, at the same time, limits interaction to the use of only one hand or wand (Figure 1.4, center), and is therefore not commonly used.

To enable direct 3D interaction for hand-held AR, an alternative is to use the changes of the device pose for 6 degrees-of-freedom (DoF) interaction. This technique enables a direct 3D mapping between the user actions and subsequent changes in an object's pose, and also a wand-like selection with the hand-held device. Furthermore the device pose-based interaction technique is able to reduce 

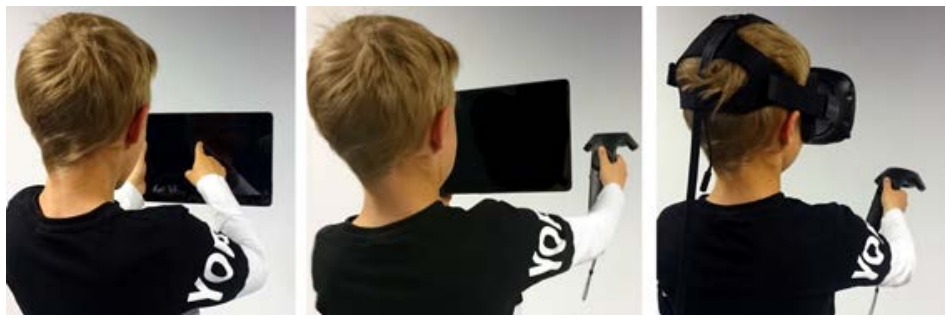

Figure 1.4: Augmented Reality interaction examples. From left to right: hand-held with touch, hand-held and wand, and head mounted display and wand.

finger occlusion and can also decrease fatigue by enabling a continuous control while holding the device with both hands. creating a robust interaction technique for hand-held AR, is another of the challenges that this thesis addresses, as presented in Chapter 3.

\subsection{Contributions}

This thesis focuses on hand-held video see-through AR within which two general aspects of AR; graphics, and interaction are addressed. In chapter 2 and 3 the concepts and methods developed within this research are described, where chapter 2 focuses on rendering and chapter 3 on interaction. In chapter 4 , first a survey of important performance metrics for evaluation of interaction in virtual environments is presented, followed by the description of five formal user studies performed throughout this research to evaluate the techniques presented in chapters 2 and 3. Finally, a summary of research and conclusions are presented in chapter 5 .

The following is a short review of the main contributions of each publication included in this thesis. The author of this thesis is the first author and the main contributer of all articles included within in.

Paper A: The introduction of geometry-based user perspective rendering for hand-held video see-through Augmented Reality.

Paper B: A more elaborate explanation of the technique introduced in paper A, along with the demonstration of the presented method with two external tracking systems. The introduction of a two part system calibration method for estimations of the camera and the screen poses in hand-held video see-through Augmented Reality.

Paper C: Design, procedure and results of two formal user studies on touch interaction with hand-held video see-through Augmented Reality. In particular 


\section{Chapter $1 \bullet$ Introduction}

comparison of device perspective rendering with user perspective rendering for a find and select task, and also a pose manipulation task, respectively.

Paper D: The introduction of a device pose-based manipulation method based on user perspective rendering. Also, the presentation of our formal user study on the device pose-based manipulation, comparing the introduced method with the existing ones that are based on the device perspective rendering.

Paper E: A summary of evaluation principles used for, or developed explicitly for, virtual environments together with a survey of quality metrics used in user-based IT evaluations, based on 15 publications on this topic. In particular categorization and analysis of the user studies to establish baseline performance metrics used for evaluations in VR and AR.

Paper F: An analysis of touch and non-touch selection and manipulation in handheld video see-through AR. The introduction of a new approach to selection with minimal touch and hand movements, as well as the introduction of a new device pose-based manipulation for fast, precise and continuous pose control.The design, procedure and results of two user studies comparing both new and existing techniques for selection and pose manipulation in hand-held video see-through Augmented Reality are also presented. 


\section{User Perspective Augmented Reality}

With hand-held video see-through Augmented Reality (AR) a camera is used to capture the view of the real world and render it on screen along with graphical augmentations. Two perspectives are used to render the AR view: one creates the same view on the screen as the view of the camera, which is called device-perspective rendering (DPR), while the other creates a view based on the relative position and orientation of the user's view and the screen, which is called user-perspective rendering (UPR). Section 1.3 described that UPR reduces the misalignment between what is rendered on the screen and what is visible around it, which is introduced by DPR. UPR creates a view that changes dynamically based on the relative pose of the user's point of view and the screen, which requires continuous tracking of the pose of the screen and the position of the user's view. It is worth mentioning that since with hand-held devices stereo vision is not commonly used, here the user's eye position means a position between the user's eyes.

There are a number of approaches to video see-through AR with UPR. The works of Yoshida et al, Hill et al [19], and Tomioka et al [48] are examples of these approaches. To my best knowledge most of the user perspective-based AR methods use homography transformation to create the view of the world and track the pose of the camera and thus the screen. Homography-based tracking relates a number of feature points in adjacent frames of an image sequence to determine the relative camera positions, for further information see [6, 32]. Accurate 3D pose estimation using homography is still an open problem which is dependent on several variables such as the camera and the environment. Consequently it is expected that the use of homography-based tracking for UPR will introduce some registration inaccuracies. For example Tomioka et al [48] stated that using homography-based 


\section{Chapter 2 - User Perspective Augmented Reality}

tracking in their UPR hand-held AR cause some registration error as the result of detection errors of both the scene and the face. They also stated that while using their system they experienced both jitter, caused by instability in homography, and latency, as the result of expensive detection and pose estimation calculations.

We suggest an alternative approach to create hand-held video see-through AR with UPR using projective geometry, based on Virtual Reality principles, introduced in Paper A and further explained in Paper B.

Despite the fact that UPR, compared to DPR, decreases the amount of misalignment by aligning the AR view to the user's view, it can still be impacted by other sources of registration error. For instance inaccuracy in tracked poses of the screen and the camera are two sources of registration error which will result in some misalignment between the view of the real world seen on and around the screen, and the graphical virtual augmentations. To resolve this problem we create a two-part semi-automatic calibration technique, introduced in Paper B, which provides more accurate poses of the camera and the screen relative to the externally tracked hand-held device.

\subsection{Geometry-based User Perspective Rendering}

In Virtual Reality (VR) where the screen is stationary, sometimes called desktop Virtual Reality, the position of the user's eye along with the position and the size of the screen, is commonly used to create a view which is aligned with the user's view. For examples of desktop Virtual Reality see [14, 33]. In VR the virtual objects are projected onto the same screen as if they were positioned in the real world. For details of this technique we refer to [50]. We use this principle to create our geometry-based UPR AR.

There are a few fundamental differences between the desktop VR and hand-held video see-through AR which make our method different. Desktop VR uses stationary screen with a constant pose as opposed to hand-held AR, for which the screen is mobile. Therefore, a dynamic pose tracking is required to track the screen. Furthermore, in video see-through AR a camera is used to add the view of the real world, which introduces a need to align this view with the view of the virtual world.

We use the dynamic poses of the screen, the camera and the user's view to estimate a view for the on-screen graphics which is aligned with the user's actual view in real-time. In the geometry-based method we use 3D tracked data that can be provided by an external tracking system. The result doesn't suffer from the homography inaccuracies which would lead to jitters, and latency. However, using an external tracking system adds restrictions: such systems are expensive, need to be setup and calibrated, work in a limited environment and often need markers, emitters, or detectors on the tracked devices. However, having an accurate pose 
tracking enables the focus to be on the rendering issues while the tracking can easily be replaced by any other method, since it is isolated from the rendering.

\subsubsection{Dynamic Virtual View}

With geometry-based UPR we thus create and continuously update a virtual perspective, dynamic virtual view, to replicate the user's actual perspective. This view is used to render the real world image along with the virtual augmentations on the screen.

In graphics APIs, such as OpenGL, the view settings are typically divided into two homogeneous matrices, a view matrix, and a projection matrix. The view matrix corresponds to the extrinsics of the view and controls the pose of the virtual view. We align the position of this view with the position of the real view, and thus with the position of the user's eyes. Furthermore, we define a projection plane, the near plane in OpenGL, parallel to the screen, which makes the projection of virtual objects in correct perspective from the user's point of view. The orientation of the virtual view is aligned with the near plane and thus with the screen, see Figure 2.1. We form the view matrix from the position and orientation of the virtual view as

$$
M_{\text {view }}=\left(\begin{array}{c|c}
R_{\text {screen }} & \vec{t}_{\text {eye }} \\
\hline 0 & 1
\end{array}\right)
$$

where $M_{\text {view }}$ is a $4 \times 4$ view matrix, $R_{\text {screen }}$, is the orientation of the screen in the form of a $3 \times 3$ matrix, and $\vec{t}_{\text {eye }}$ is the position of the user's eye as a $3 \times 1$ vector.

The projection matrix corresponds to the intrinsics of the view, such as the field of view and skew, and expresses the shape of the virtual view as a truncated pyramid called the view frustum. This frustum will govern how objects are projected into the screen. A way to define the frustum is by its six boundary planes called: near, far, left, right, top, and bottom, see Figure 2.1. The distances of the near and far planes are not important for the projection, as long as all objects are between these two planes. The other planes are defined to pass through the center of the view and each contain one of the screen edges. These planes also intersect with the near plane and so can be estimated by their distances from the projection of the user's eye position on the near plane. The estimated frustum is used by graphics APIs to calculate the projection matrix. For a reference in OpenGL see [45].

Figure 2.1 illustrates how we define and estimate the view frustum in the geometrybased method. The relative movement of the eye position and the screen changes the shape of the frustum. To keep the correct perspective from the user's point of view our method dynamically estimates the shape of the frustum using 3D geometry. For example, the left frustum plane is estimated as follows:

First, the projection of the eye position on the plane of the screen is estimated as 


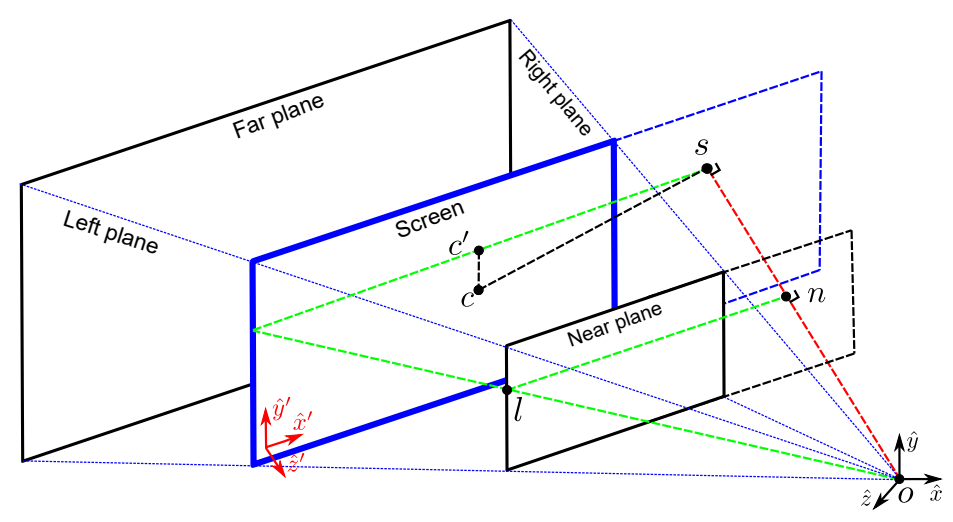

Figure 2.1: The graphics API's view and frustum with the geometry-based UPR method, which aligns $o$ the center of the virtual view with the user's view. $l$ is the position of the left frustum plane on the near plane, and $s$ is the projection of the eye position, $o$, onto the screen whose center is shown by $c . \hat{x}, \hat{y}$, and $\hat{z}$ are right, up, and back in the view's frame of reference, respectively, and the $\hat{x}^{\prime}, \hat{y}^{\prime}$, and $\hat{z}^{\prime}$ are the same vectors in the screen's frame of reference.

$$
\vec{s}=\vec{o}+\hat{z}^{\prime}\left(\hat{z}^{\prime} \cdot(\vec{c}-\vec{o})\right)
$$

where $\vec{o}$ and $\vec{c}$ are the view and the screen centers, respectively. $\hat{x}^{\prime} \hat{y}^{\prime} \hat{z}^{\prime}$ are right, up and back, respectively, in the screen's frame of reference.

The similar triangles are then used to estimate the distance of the left plane from the projection of the eye position on the near plane as

$$
d_{l}=\frac{d_{n}}{|\vec{s}-\vec{o}|}\left(\hat{x}^{\prime} \cdot(\vec{c}-\vec{s})+\frac{1}{2} w\right)
$$

where $w$ is the width of the screen, $d_{n}$ is the distance of the near plane from the eye position, and $\vec{o}$ is the projection of the eye position.

\subsubsection{Real World View}

It is not possible to see the real world through the opaque screen of hand-held device, therefore, to create the see-through effect, the live view of the real world is captured by a camera. This captured view is merged with the virtual augmentations and displayed on the screen. In hand-held AR the camera is commonly mounted on the back of the device. To correctly align the real world view and the captured 


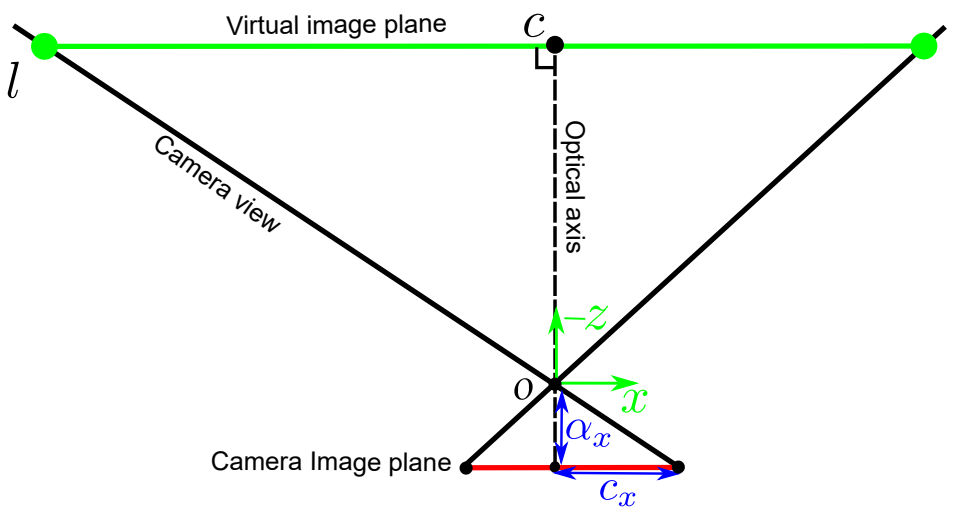

Figure 2.2: The geometry-based method creates a virtual camera image as a rectangle parallel to the real camera image plane. $l$ shows the left side of the virtual image plane and $o$ shows the camera center. $-z$ and $x$ are the front and right side in the camera's frame of reference, respectively. $\alpha_{x}$ and $c_{x}$ are the $x$ components of camera's focal length and principal point, respectively, expressed in pixels.

video feed on the screen, we need both the extrinsic and the intrinsic parameters of this camera. The extrinsic parameters define the camera's position and orientation relative to the real world while the intrinsic parameters link the pixel coordinates of the camera image with the real corresponding points in the camera's frame of reference. We use a tracked camera and thus the extrinsic parameters are available for each frame, based on the movement of the camera. furthermore, we estimate the camera intrinsics in the camera calibration process.

With our geometry-based method, we render the captured video feed of the real world on a textured rectangle, which represents the camera's virtual image plane in the virtual world. This virtual image plane is placed in the virtual view parallel to the image plane of the camera, while sharing a same optical axis. Figure 2.2 shows how the virtual image plane is aligned with the camera.

The virtual image plane can be placed in the virtual view at an arbitrary distance to the camera's image plane in front of the user's eye position. We estimate the boundaries of this rectangular plane using the distances of each side from its center. For example we estimate, $d_{l}$, the distance from the center to the left side, based on the similarity of triangles as

$$
d_{l}=d_{c} \frac{c_{x}}{\alpha_{x}}
$$

where $d_{c}$ is the arbitrary distance of the virtual image plane from the camera, $\alpha_{x}$ and $c_{x}$ are the $x$ components of the camera's focal length and the principal point 

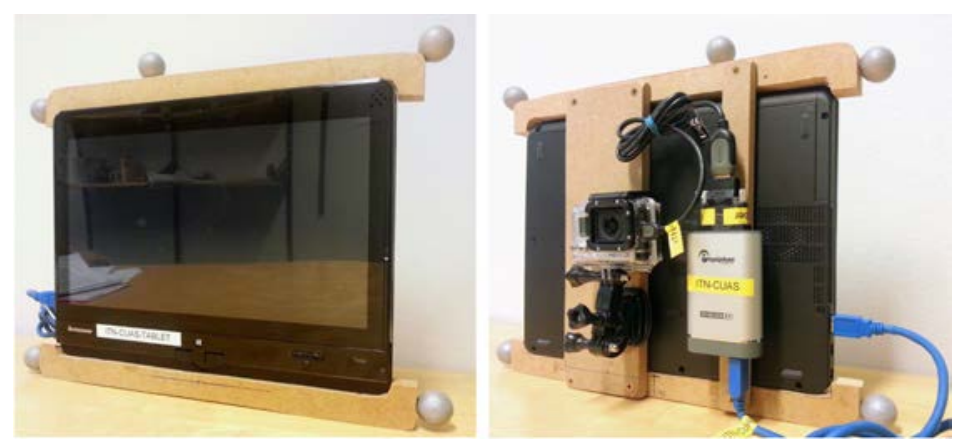

Figure 2.3: Front and back side of the UPR video see-through AR system prototype: A wooden frame holds the tablet computer, the camera, the frame grabber, and IR reflector markers.

respectively, expressed in pixels.

Based on the field of view of the dynamic virtual view, the virtual image plane may be completely or partially inside the view and thus accordingly visible on the screen. It is also possible for the virtual view to move completely out of the field of view of the camera, making the virtual image plane not visible on the screen. Furthermore it is worth mentioning that a wider field of the view of the camera leads to a wider virtual image plane, which consequently affects its visibility inside the virtual view.

\subsubsection{Prototype and System Demonstration}

We have demonstrated the geometry-based UPR technique in a test scenario where our hand-held AR prototype was used to follow a quadcopter. Figure 2.3 shows the prototype which we developed to demonstrate our UPR hand-held video see-through method.

\section{Hardware and Implementation}

A Lenovo Twist convertible tablet PC was used as video see-through rendering display. The live video feed was captured with a GoPro Hero3 (Black Edition) that is able to capture Full HD video and has a lens with $170^{\circ}$ horizontal field of view. The video was captured from HDMI using an Epipan DVI2USB 3.0 frame grabber, at 30 frames per second. We mounted the tablet and the camera on a wooden frame which was also used as the housing for the grabber and the tracked markers.

We developed and tested our prototype in an environment equipped with a Vicon tracker. Vicon is capable of fast and accurate 3D tracking of multiple objects simultaneously. We attached infrared reflective markers to all tracked objects, 
including the tablet frame, to track the screen and camera, a pair of safety glasses, to track eye position, and also the quad-copter.

The communication of tracker information between the tracking system and the AR system was implemented in Robot Operating System (ROS). The video see-through AR software was developed in the $\mathrm{C}++$ programming language, OpenGL [45], and GLSL (OpenGL Shading Language). For the image capture, calibration, and rectification we used OpenCV [10]. To access input devices and graphic hardware we used SDL (Simple DirectMedia Layer) [1].

\section{System Demonstration and Results}

The demonstration scenario was designed to replicate a real life application of the hand-held AR, where we followed a quadcopter using our AR enabled prototype. Figure 2.4 shows the execution of the demonstration. To illustrate the various parts of the geometry-based UPR method we added graphical representations of the virtual dynamic frustum and image plane, along with the user's head, the screen, and the quadcopter, to the image. To show the effect of our method we ran the demonstration twice using both DPR and UPR perspectives which led to different usage experiences: the DPR's fixed view required a similar amount of device movement to follow the quadcopter, flying with no acceleration, while the dynamic field of view, and view direction for UPR affected the amount of movement required to follow the quad-copter.

For example, throughout the demonstration, it was possible to move the head to correct the perspective and follow the quadcopter. Holding the device closer to the eyes provided a larger field of view and therefore required less movement. Figure 2.5 shows the sequential images of the system demo, using both the DPR (first row) and UPR (second row). It can be seen in the images that our UPR method reduces the registration error between the real quadcopter, and both its appearance in the video feed and its virtual augmentation rendered on the screen. Through the demonstration we observed that the geometry-based UPR method made the quadcopter always visible on the screen when it was behind the screen, regardless of position or orientation of the camera, tablet or the head.

\subsubsection{Reality and Virtuality Alignment}

To achieve the goal of simulating a see-through frame with UPR we have to align three views of the world: (1) the camera view which is captured by the back facing camera and is shown on the screen, (2) the virtual view where the virtual augmentations are also shown on the screen, and (3) the real view, which the user can see around the screen. The camera is mounted on the back of the screen and so is not co-located with the user's eye. Therefore, what the camera and user see are not the same, resulting in some misalignment between the camera view and real view. 


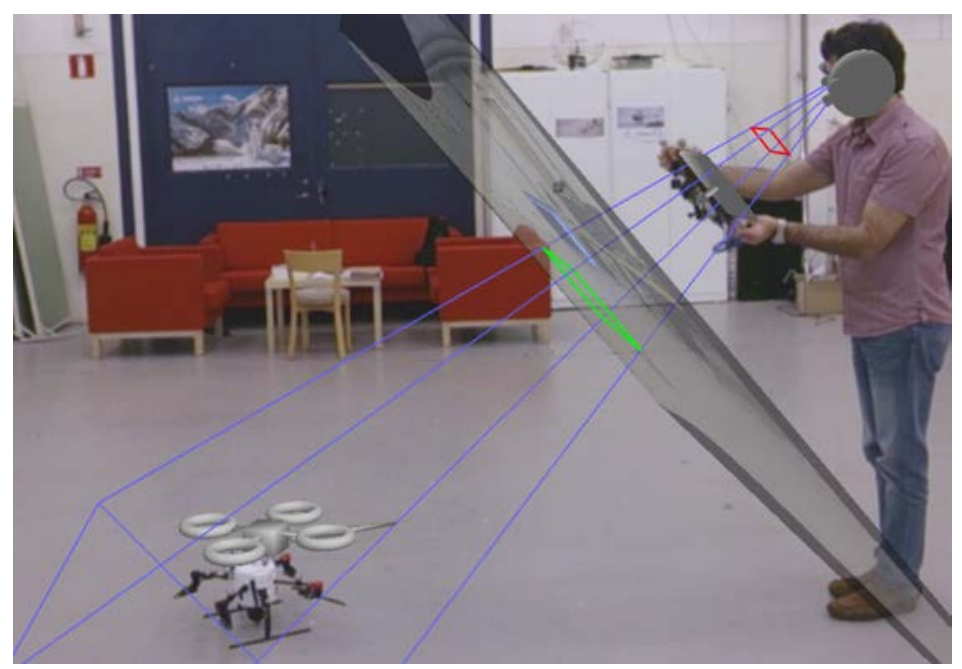

Figure 2.4: Our system test: following a flying quadcopter using the AR enabled prototype. The blue lines show the virtual view as the graphics API's dynamic frustum with its near plane specified by a red rectangle. The green rectangle specifies a part of the virtual image plane which is visible on the screen. For illustration purposes we also added the computer graphics rendering of the user's head, the screen, and the quadcopter.
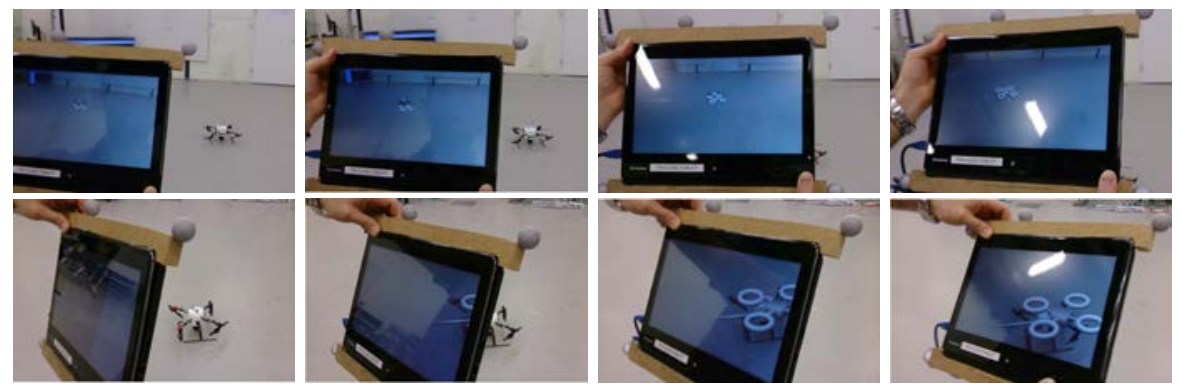

Figure 2.5: Sequential pictures of the running system test with the DPR (first row) and UPR (second row) views. The DPR sequence shows some misalignment between the the real world, visible around the screen, and both the video feed, and the augmentation, and from the user's point of view. The UPR sequence shows that the latter misalignment is reduced using the geometry-based UPR technique. 


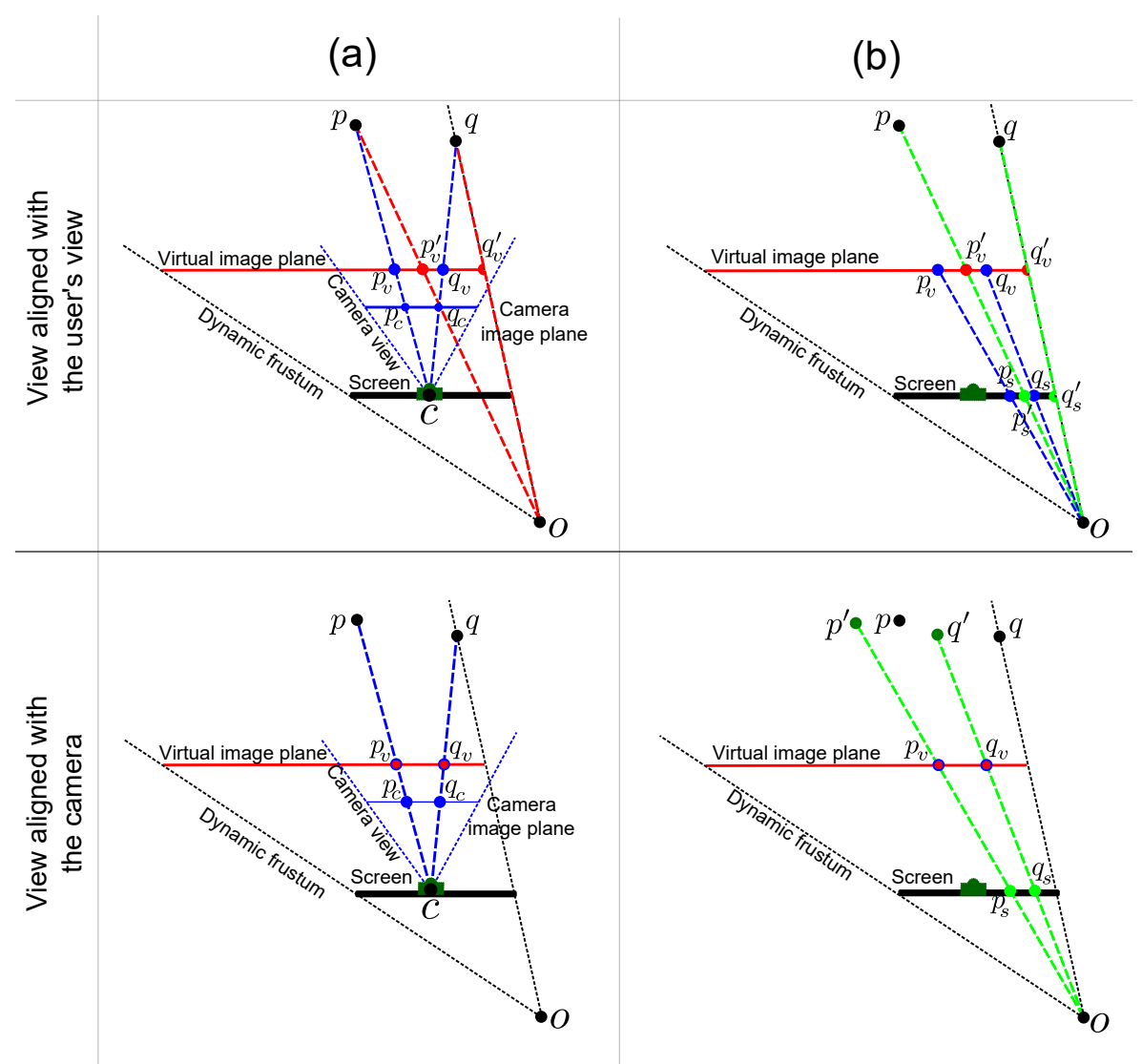

Figure 2.6: Alignments of the virtual view with the camera view and the view of the real world in the geometry-based UPR. 1) The center of the view aligned with the user's eye position: (a) $p_{c}$ and $q_{c}$ are the projections of the real objects, $p$ and $q$, on the image plane of the camera. $p_{v}^{\prime}$ and $q_{v}^{\prime}$ are the projection of the $p$ and $q$ on the virtual image plane from the center of the view, which are not co-located with $p_{v}$ and $q_{v}$ the projections of the real objects from the camera center. (b) $p_{s}^{\prime}$ and $q_{s}^{\prime}$ are the on screen render of the virtual augmentations for the real objects which are not co-located with, $p_{s}$ and $q_{s}$, the screen render of the objects in the video feed. From the user's point of view, however, $q_{s}^{\prime}$ is aligned with the part of the real object $q$ which is visible from the left side of the screen. 2) The center of the view aligned with the camera center: (a) The the projections of the real objects on the virtual image plane are co-located with their projections from the image plane of the camera, at $p_{v}$ and $q_{v}$. (b) The on screen render of the virtual augmentations and their corresponding objects in the video feed are aligned at $p_{s}$ and $q_{s}$. From the user's point of view, however, the on screen render of the objects are aligned with the real objects as if they were placed at $p^{\prime}$ and $q^{\prime}$. 
As discussed in 2.1.1, we place the center of the virtual dynamic view at the user's eye position and also move the rendering of the camera view to this position, to align the virtual and real views. This view configuration increases the alignment between the real view and the virtual view from the user's point of view. However, it introduces some misalignment between the camera view and the virtual view on the screen, as explained in Figure 2.6(1).

We can decrease the misalignment between the camera view and virtual view by co-locating the center of the dynamic view with the camera center. However the introduced offset will create some misalignment between the real and virtual views, see Figure 2.6(2).

Here there is a trade-off between the alignment of the virtual view with either the real view or the camera view. The video feed and the augmentations are both rendered on the screen while the real world is visible from around the screen. We believe that in AR the user's center of focus is more on the screen, where the virtual augmentations are displayed, rather than around it. Therefore the on-screen misalignments will be visually more apparent than the ones between the on-screen content and the real world around it.

Co-location of the dynamic view with the camera center changes the previously calculated view matrix, $M_{\text {view }}$, in Equation 2.1 as

$$
M_{\text {view }}=\left(\begin{array}{c|c}
R_{\text {screen }} & \vec{t}_{\text {camera }} \\
\hline 0 & 1
\end{array}\right)
$$

where $R_{\text {screen }}$ is the orientation of the screen and $\vec{t}_{\text {camera }}$ is the position of the camera.

\subsection{System Calibration}

As discussed in 2.1.4, a source of registration error in the geometry-based UPR is the displacement of the user's eye and the camera. However, there are other registration errors which are caused by misalignment between the poses of the system parts, such as the screen and the camera, and their tracked poses. In geometry-based UPR, we use the pose of the screen and the camera to create the UPR view. We use external tracking, which tracks markers attached to the screen and provides the pose of the frame of these tracked markers. Misalignments between the poses of this frame of markers and both the screen and the camera cause registration errors between the camera view and both the real view and the virtual view.

The latter errors can be reduced by using a manual measurement of the misalignments between the parts of the system but this often needs special equipment and is time consuming. Therefore we created a two-part semi-automatic rig calibration 


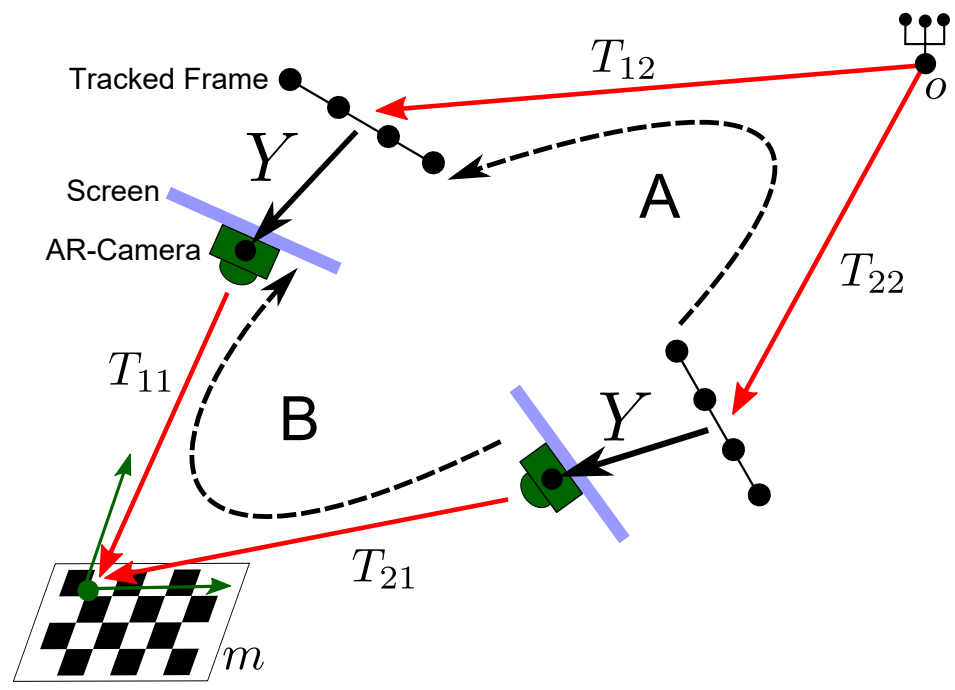

Figure 2.7: To get the pose of the camera we estimate the rigid transformation, $Y$, between the tracked-frame around the hand-held device and the camera mounted on the back of the device. The tracked frame houses markers which are tracked by the external tracking system. The fiducial marker, $m$, is used to estimate the camera pose in the marker's frame of reference. Using two different poses of the device $Y$ is estimated by reforming the problem into the equation $A Y=Y B$. The marker, $m$, and the origin in the tracking system, $o$, are fixed during the process.

method: the first part estimates the pose of the camera, and the second part estimates the screen pose. These are described in the following two subsections.

\subsubsection{Camera Pose}

In geometry-based UPR the tracked pose of the camera is not directly provided by the external tracking system. Furthermore, with our prototype the tracked markers are attached to a frame that holds the hand-held device (Figure 2.3) and the pose of this frame is provided by the external tracking system in its frame of reference. The pose of the camera and the tracked-frame are not aligned, however they are both fixed to the hand-held device and therefore have a fixed relative pose. We estimate this relative pose as a rigid transformation, $Y$, from the tracked-frame to the camera. By applying $Y$ to the pose of the tracked-frame we can estimate the pose of the camera in the reference frame of the tracking system.

Figure 2.7 shows our setup for the first part of the system calibration where we use two tracked positions of the device to estimate $Y$. We place a printed fiducial marker, $m$, in a position visible to the camera from both device placements. The 
marker is used to estimate the camera poses from both device positions as rigid transformations $T_{11}$ and $T_{21}$ in the marker's frame of reference. The poses of the tracked-frame from both device positions are provided as rigid transformations, $T_{12}$ and $T_{22}$, by the tracking system in its frame of reference. The marker, $m$, and the tracking system's coordinates are fixed throughout the calibration process. Considering the trajectory from the origin of the tracking system, $o$, to the marker, $m$, through the tracked-frame and camera for both placements of the device, as is shown in Figure 2.7, we have

$$
T_{12} Y T_{11}=T_{22} Y T_{21}
$$

Multiplying both sides of the above equation by $T_{22}^{-1}$ from the left and $T_{11}^{-1}$ from the right side we have

$$
T_{22}{ }^{-1} T_{12} Y=Y T_{21} T_{11}^{-1}
$$

$T_{22}^{-1} T_{12}$ can be interpreted as the motion made by the tracked-frame between two device placements and we denote it by $A$ :

$$
A=T_{22}^{-1} T_{12}
$$

Similarly we see $T_{21} T_{11}^{-1}$ as the motion of the camera and denote it by $B$ :

$$
B=T_{21} T_{11}^{-1}
$$

Replacing 2.7 and 2.8 in 2.6 we have

$$
A Y=Y B
$$

which is a well known equation in the field of robotics, usually called the robot-sensor calibration problem. Robotic hand/eye calibration is the process of estimating the pose of the robot sensor, usually a camera, in the frame of reference of the robot's hand, see [52]. There are many approaches to solving the $A Y=B Y$ equation. An overview of the different solutions for this problem is presented by Shah et al [43]. We have implemented and compared two of the more straight forward methods from Shiu and Ahmad [44], and Liang et al. [26]. Both methods use multiple samples, provided by various placements of the device, to estimate $Y$. To find a unique solution both methods need at least two sets of relative transformations, $A$ and $B$, provided by three different placements of the hand-held device. However they suggest using more sets of $A$ and $B$ for a more accurate estimation of $Y$. 
Table 2.1: Differences between the estimations of $Y$ using the presented methods, and its manual measurement. $Y$ is the displacement between the camera and the reference frame of the tracked markers. Here $\mathrm{x}, \mathrm{y}$, and $\mathrm{z}$ are left, up, and behind respectively in the reference frame of the markers. The translation difference is presented as total distance and also separately along each axis. The orientation difference is presented as overall angle and also separately around each axis.

\begin{tabular}{lcccccccc} 
& \multicolumn{3}{c}{ Translation $(\mathrm{mm})$} & \multicolumn{4}{c}{ Rotation $\left(^{\circ}\right)$} \\
Estimation & Distance & $\mathrm{x}$ & $\mathrm{y}$ & $\mathrm{z}$ & Angle & $\mathrm{x}$ & $\mathrm{y}$ & $\mathrm{z}$ \\
\hline Method 1 & 8.78 & 7.5 & -4.2 & 1.8 & 1.52 & 0.92 & 0.83 & -0.89 \\
Method 2 & 2.78 & 2.4 & 1.4 & 0.0 & 1.43 & 0.86 & 0.55 & -1.0
\end{tabular}

Table 2.1 shows the difference between a manual measurement of $Y$ in our prototype system, used as reference, and the $\widetilde{X}$, separately by both implemented methods, using 10 sets of $A$ and $B$ rigid transformations. We did the manual measurement of the prototype device on its images in a graphics application. The results show an over all smaller deviation from the reference measurement for the second method.

\subsubsection{Screen Pose}

The pose of the screen is usually not aligned with the camera. They are, however, typically both fixed to same frame. Therefore the screen pose can be estimated if the pose of the camera and the relative pose of the camera and the screen is known. In the second part of our calibration we estimate the relative pose of the screen and camera and use it to estimate the screen pose from the tracked pose of the camera which we estimated in the previous part.

We estimate the relative pose of the screen and camera as the rigid transformation $X$ from the center of the screen to the camera center, see Figure 2.8. Here we use a second camera $\left(c_{2}\right)$, pointing towards the screen, a printed fiducial marker $\left(m_{1}\right)$ visible from both cameras, and also a second fiducial marker $\left(m_{2}\right)$ which is displayed on the screen.

Our calibration method uses the marker, $m_{1}$, to estimate the pose of the cameras, $c_{1}$ and $c_{2}$, as rigid transformations, $T_{1}$, from $c_{1}$ to $m_{1}$, and $T_{12}$, from $c_{2}$ to $m_{1}$, in $m_{1}$ 's frame of reference. The on-screen marker, $m_{2}$, is used to estimate the pose of the camera, $c_{2}$, in the screen's frame of reference as the rigid transformation $T_{2}$. The transformations $T_{1}, T_{2}$, and $T_{12}$ are estimated using Perspective-N-Point $(\mathrm{PnP})$ with the real measurement of the marker corner points and the detected marker corner points from the camera images as the set of point correspondences. For details of PnP see, for example, [17].

Considering two trajectories between the centers of the screen and the camera, $c_{1}$, we calculate an estimation of the rigid transformation $X$ as 


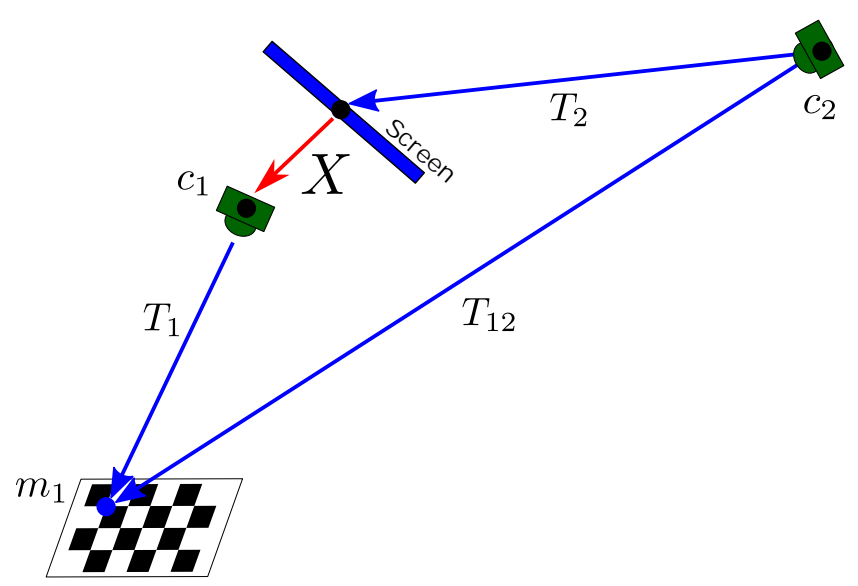

Figure 2.8: The rigid transformation $X$ between the screen and the camera $c_{1}$ is estimated using $c_{2}$, a secondary camera, $m_{1}$ a printed marker, and $m_{2}$ a marker which is displayed on the screen. $t_{m s}$ is the misalignment between the center of the displayed marker, $m_{2}$, and the screen center measured as a $2 \mathrm{D}$ translation.

$$
\widetilde{X}=T_{2}^{-1} T_{12} T_{1}^{-1}
$$

The accuracy of the $\widetilde{X}$, by the PnP solver, is affected by the noise in the detection of the corner points on the fiducial markers. We refine our estimation of $X$ by averaging over multiple $\widetilde{X}$, which are separately estimated by changing the relative pose of the hand-held device, the printed marker $m_{1}$, and the second camera $c_{2}$ without changing the relative pose of the screen and the camera $c_{1}$ on the hand-held device.

To test the accuracy of the presented method we compared the average $\widetilde{X}$ over 27 separate estimations with a manual measurement of $X$ which is used as reference. Figure 2.9 shows the translation and rotation differences, of each $\widetilde{X}$ and their mean values. The results show that the difference from the reference is up to $0.24 \mathrm{~mm}$ for translation and up to $0.65^{\circ}$ for rotation. If there is no systematic bias in our estimation, which we have not found so far, considering the small deviation in $z$ rotation, it is reasonable to believe that our estimation is more accurate than the reference that is based only on one measurement. 


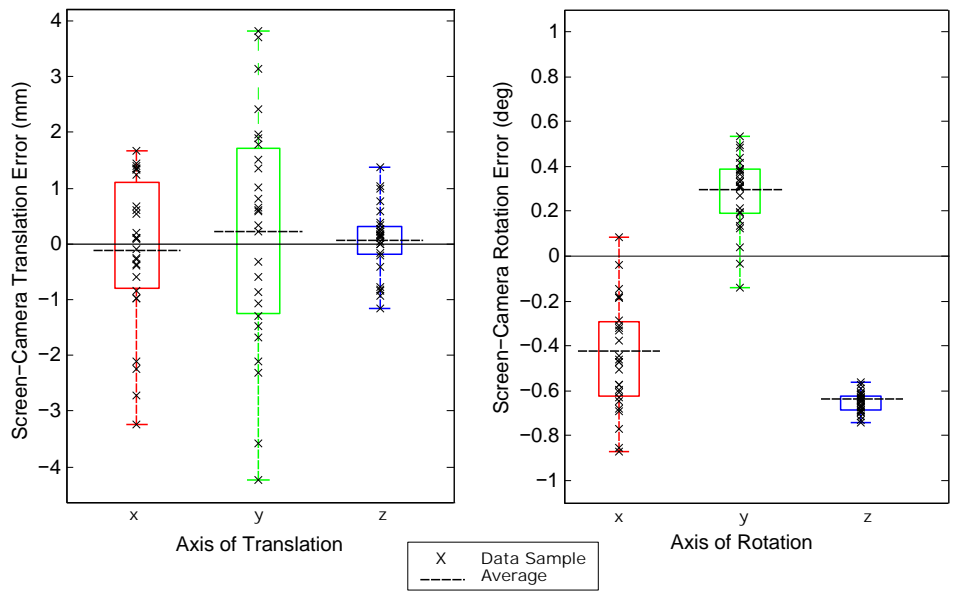

Figure 2.9: plot of differences between 27 separate estimations of $X$, their averages, and the manual measurements of our prototype system. $X$ is the relative pose of the screen and camera, and is estimated using the presented method. Left: The translation difference along each axis in millimeters, Right: The rotation difference around each axis in degrees. The boxes show the interquartile range, and the whiskers represent the minimum and maximum. 



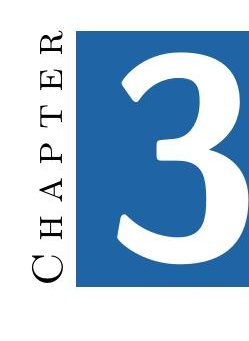

\section{Device Pose-based Interaction}

Touch-based on-screen interaction techniques are commonly used in hand-held video see-through Augmented Reality (AR) for selection and manipulation of virtual objects. As discussed in section 1.4, however, they lack direct 3D control, and suffer from finger occlusion and fatigue.

Direct 3D control can be achieved in hand-held AR by using the device as a wand. This provides direct 3D mapping between control and motion, and thereby allows both intuitive and high precision control in 6 degrees-of-freedom pose manipulation. In the remainder of this thesis we will call this technique device pose-based manipulation (DM).

\subsection{DPR Device Pose-based Manipulation}

With DM, the changes in the pose of the device are mapped to a virtual object which is manipulated. To the best of our knowledge, the first example of DM in the literature is by Henrysson et al. [18]. Other examples are from Katzakis and Masahiro [23], Du et al. [12], and Sasakura et al. [41]. In the literature there are two general approaches towards DM, with their difference being mainly in the technique they use to map the changes between the poses of the device and the manipulated object. These techniques are both based on the device perspective rendering (DPR).

The first approach, which we call fix- $D P R$, maps the pose changes to the object as if it is locked to the hand-held device (Figure 3.1[1a]). Thus, the virtual object is moved with the device as if they are connected by a virtual rod (Figure 3.1[1b]), for 
examples of this approach to DM see [41, 47]. The issue with fix-DPR stems from the fact that the virtual object and the hand-held device share the same center of rotation, which makes it difficult to rotate the virtual object without translating it, (Figure 3.1[1c]). Furthermore changing the orientation of a virtual object is not possible at a distance not reachable by the user.

The second approach, which we call relative- $D P R$, directly maps the device pose to a virtual object. Relative-DPR translates and rotates the virtual object by the same amount as the device and in the same direction (Figure 3.1[2b]), an example of this technique is presented in [30]. Unlike the fix-DPR it is possible to rotate a virtual object without translating it (Figure 3.1[2c]). Relative-DPR, however, introduces two issues: rotating the device will also rotate the camera and consequently will rotate the virtual view. This results in moving the virtual object, partially or completely, out of the on-screen view throughout the yaw and pitch rotations (Figure 3.1[2c]).

The other issue is caused by using one-to-one translation mapping: The same amount of translation that is mapped from the device to the virtual object appears smaller in perspective, which increases with the distance between the virtual object and device. This, consequently may result in moving the virtual object out of view (Figure 3.1[2b]). It is a matter of the size difference between the action space and the workspace. With the additional distance of the manipulated object the size of the work space increases while the size of the action space does not change. For instance when working with an object that is one kilometer away the actual work space that the object is moved within is kilometer size which means that we have an action range of about one meter to manipulate an object that might need to be moved one kilometer.

\subsection{UPR Device Pose-based Manipulation}

In an effort to reduce the discussed issues of both existing DM techniques, we take advantage of user perspective rendering (UPR) for DM. We first present a UPR-based version of the relative-DPR method, which we call relative-UPR, that is presented in Paper D. Then we introduce another DM method, which we call fix-UPR, that is introduced in Paper F.

Relative-UPR has the same mechanics as relative-DPR: the translation and rotation are both directly mapped from the device to the manipulated object and so the object is moved in the same direction and by the same amount, see Figure 3.2[b,c]. However, as the result of using the user's perspective, rotating the device does not change the orientation of the AR view, which keeps the manipulated object in the view during rotation. Figure 3.3, shows both DPR-based DM techniques along with the relative-UPR used to change the orientation of a virtual chair. 
(1)

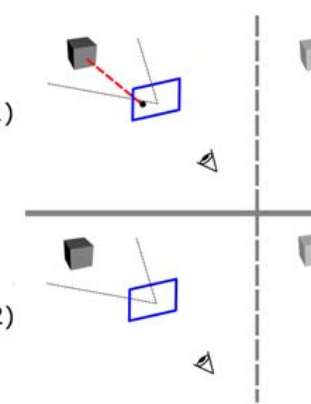

(a)

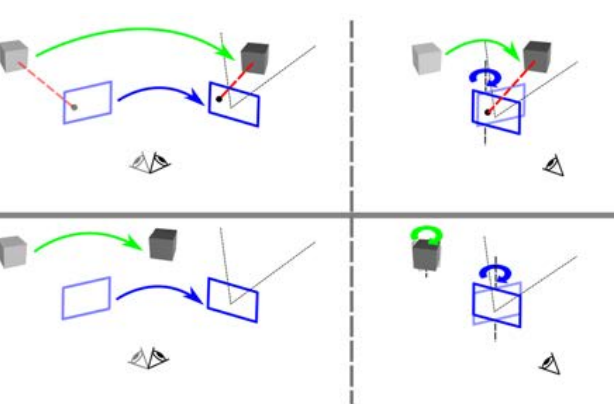

(b)

(c)

Figure 3.1: device pose-based manipulation techniques using device perspective rendering. (1) fix-DPR: (a) virtual object is locked to the device, (b) moving the device moves the virtual object as if they are connected by a virtual rod and thus the virtual object stays in the AR view, (c) rotating the device rotates and translates the virtual object and therefore, it is difficult to rotate the object without moving it. (2) relative-DPR: (a) a virtual object is selected, (b) the virtual object is moved by the same amount as the device but in perspective and therefore, it moves out of the AR view, (c) rotating the device rotates the virtual object with same amount around its own center. It is possible to rotate the virtual object without translating it, however rotating the device rotates the AR view and thus the virtual object moves out of AR view.

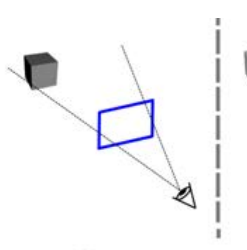

(a)

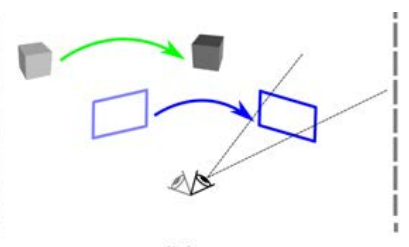

(b)

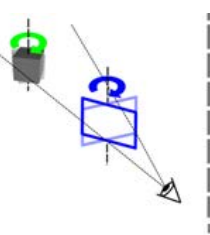

(c)

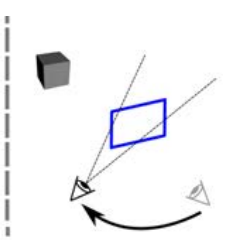

(d)

Figure 3.2: Relative-UPR device pose-based manipulation technique: (a) The virtual object is selected for pose manipulation, (b) the virtual object is moved by the same amount as the device but in perspective and therefore moves out of the AR view, (c) the virtual object is rotated by rotating the device, which with UPR does not rotate the AR view. (d) Moving the user's view changes the AR view which moves the virtual object out of the user's view. 


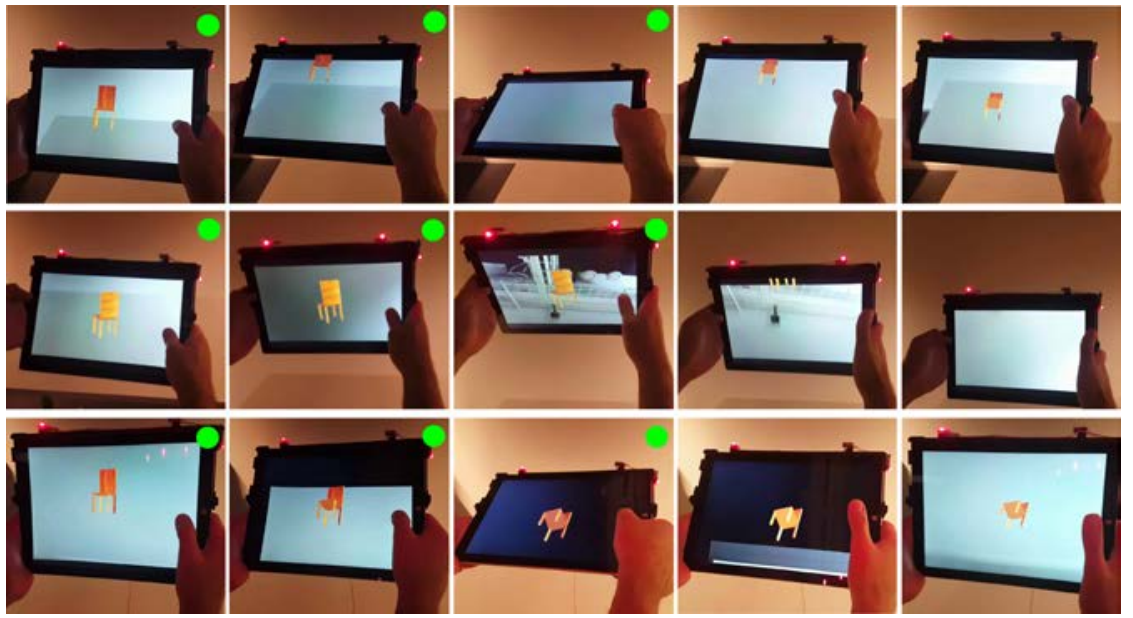

Figure 3.3: Rotating a virtual chair using three DM techniques. Green circles indicate that the virtual object is selected for manipulation. First row; relativeDPR: virtual object is rotated relative to device. Rotating the device moves the virtual object out of the user's view. Second row; fix-DPR: virtual object is locked to the device. Rotating the device rotates and also translates the virtual object. Third row; relative-UPR: object rotates relative to the device. The view is aligned with the user's perspective and thus isn't changed when the device is rotated. Virtual object stays visible on the screen during the rotation.

With relative-UPR we resolve the rotation issues of its DPR version but the translation issue caused by the one-to-one mapping for the objects that are further away remains, see Figure 3.2[b]. With relative-UPR, also, moving the user's view moves the AR view, which can potentially move the manipulated object out of the view on the screen, see Figure 3.2[d]. To resolve these issues, and keep the object in the view during manipulation, we introduce an alternate UPR-based approach to DM, Fix-UPR.

With fix-UPR we use the changes in both the device pose and the position of the user's view to move the manipulated object. These changes are mapped to the object as if it is locked to its projected position on the screen, as defined by the user's view position, see Figure 3.4[a]. Here, regardless of how the view changes because of device or head movements, the virtual object is shown in the same location on the screen throughout the manipulation, see Figure 3.4[b,c,d].

In our implementation of the fix-UPR technique the orientation and position of the manipulated virtual object are controlled in different ways and therefore are calculated separately. The orientation calculations can be done in, for example, a $3 \times 3$ matrix representation of rotation. Figure 3.5 illustrates a virtual object that 


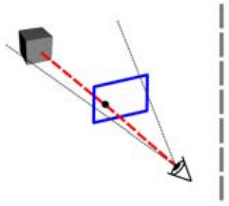

(a)

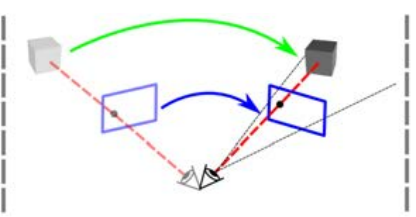

(b)

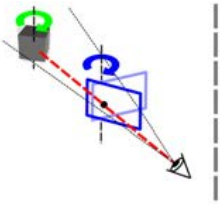

(c)

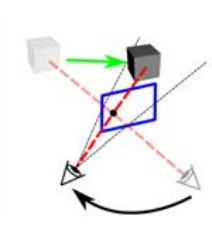

(d)

Figure 3.4: Fix-UPR device pose-based manipulation technique: (a) the virtual object is locked to its projection point on the screen as defined by the user's view. (b) moving the device the virtual object will always be visible at the projection point on the screen, (c) rotating the device with the center of rotation at the projection point will rotate the virtual object around its own center. (d) moving the user's view will move the virtual object and thus keeps it consistently visible on the screen at the projection point.

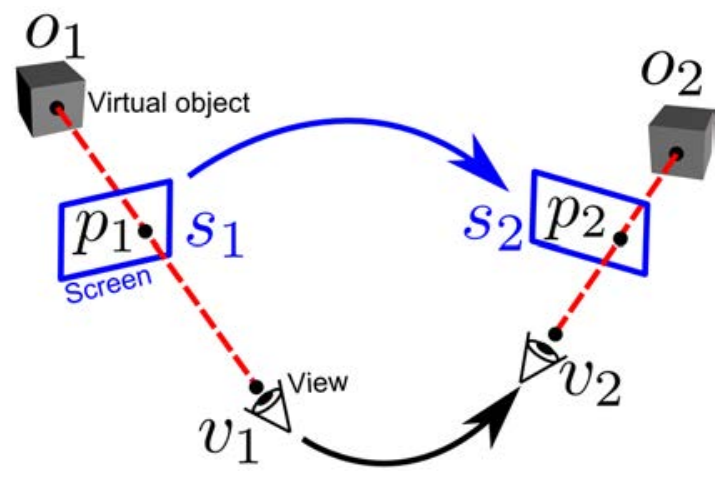

Figure 3.5: A virtual object is transformed by the fix-UPR technique from $o_{1}$ to $o_{2}$. $s_{1}$ and $v_{1}$ are the the screen and the user's view before the movement, respectively, and $s_{2}$ and $v_{2}$ are the same variables for after the movement.

is transformed, using the fix-UPR technique, from one pose, $o_{1}$, to another pose, $\mathrm{O}_{2}$. When the virtual object is selected for pose manipulation, first we calculate its orientation relative to the screen, $R_{\Delta}$, as

$$
R_{\Delta}=R_{s_{1}}^{-1} R_{o_{1}}
$$

where $R_{s_{1}}^{-1}$ is the inverse of the screen orientation and $R_{o_{1}}$ is the orientation of the virtual object when it is grabbed. The new orientation of the virtual object, $R_{\mathrm{O}_{2}}$, when the screen is rotated, is calculated as

$$
R_{o_{2}}=R_{s_{2}} R_{\Delta}
$$

where $R_{s_{2}}$ is the new orientation of the screen after the movement. The manipulated object is translated based on the relative changes in the user and screen positions, 
which is done through the object's projection point on the screen. When the virtual object is first selected, three things are calculated. First, the virtual objects projection on the screen, $p_{1}$, is calculated as the intersection between the plane of the screen and the line from the user's view center to the virtual object. The distance between the user's view and the screen point, $a_{1}$, is also needed as the user's view distance to the virtual object, $b_{1}$. After this, when the screen pose is changed from $s_{1}$ to $s_{2}$, a new projection point, $p_{2}$, can be estimated based on how the screen is moved:

$$
p_{2}=T_{s_{2}} T_{s_{1}}^{-1} p_{1}
$$

where $T_{s_{1}}$ and $T_{s_{2}}$ are $4 \times 4$ column transformation matrices in homogeneous coordinates for the initial and new screen poses, respectively. Since the screen can be moved closer or further away from the user's view, this depth motion is also used to intuitively move the virtual object in the depth direction. Thus the new position for the virtual object, $x_{o_{2}}$, is calculated as

$$
x_{o_{2}}=v_{2}+\frac{b_{1}}{a_{1}}\left(p_{2}-v_{2}\right)
$$

\subsection{Device Pose-based Selection}

In most cases of interaction with a virtual object, manipulation is subsequent to selection of the same object beforehand. The used selection technique is, therefore, also important in the overall process of interaction. On hand-held devices, when multi-touch pose manipulation is used, it is natural to also use touch for selection. With DM, however, touch selection reintroduces the issues seen in touch-based interaction, such as occlusion and fatigue.

\subsubsection{Background}

There are a number of non-touch, device pose-based selection techniques: Baldauf and Fröhlich presented two techniques they call "Target" and "Snap Target" [4]. Their Target selection uses a centered cross-hair while the Snap Target applies a dynamic cross-hair that snaps to a selectable object when it is near to the center of the screen. They compared both techniques along with touch selection in a user study. They could not find any significant difference in the performance of the compared techniques, however, the touch selection resulted in significantly larger number of selection errors.

Two other selection techniques were introduced by Tanikawa et al. "Rod" and "Center", which they used with their DM technique, and evaluated compared to touch selection [47]. The Rod technique selects a virtual object located at the tip of a virtual rod shown on the screen. The Center technique, uses an "aiming point" that is shown at the center of the screen (identical to Target technique described above). They compared these selection techniques in a JENGA-like game. 

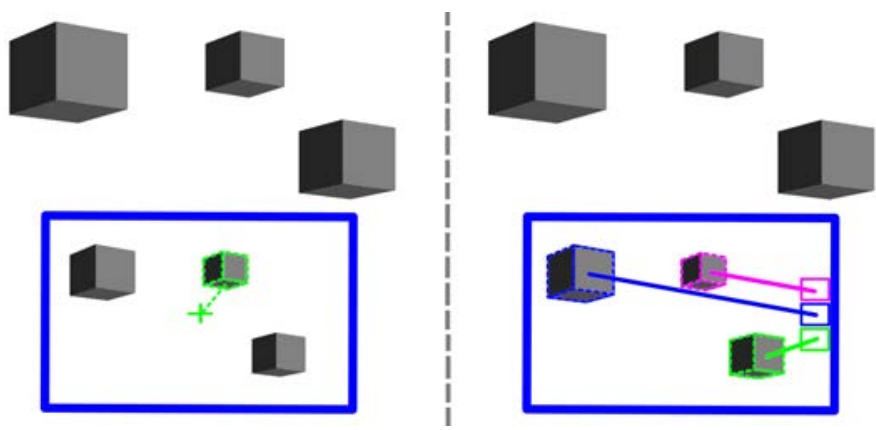

Figure 3.6: Device pose-based Selection. Left, center-select: The nearest virtual object to the center of the screen can be selected. Right, icons-select: virtual objects are assigned to icons and are selected by their corresponding icons.

\subsubsection{Modified Center Selection}

Using the center of the screen to select multiple objects require a fair amount of device movement which can result in fatigue. To reduce the overall amount of device movement we suggest a minor modification of the center select technique.

A basic implementation of a center-based selection technique would pick a virtual object when it is at the center of the screen. The snap-target modification [4] increases the reach and reduces the necessary precision by allowing the selection of objects near the center of the screen. Our modification, allows the selection of the virtual object closest to the screen center anywhere on the screen, see Figure 3.6[left]. Compared to the snap-target, here the benefit is the ability to always select the nearest object rather than need to get close to it.

In our implementation the nearest object to the center of the screen is a candidate for selection, however the actual selection is done by touching at any part of the screen, which can be performed with either thumb while holding the device with both hands.

\subsubsection{Icons-based Selection}

In an effort to reduce the required device movement when selecting a number of virtual objects in sequence, we introduce an alternative technique which we call icons-select. With icons-select we assign a number of virtual objects to selectable icons which consequently provides the user with a list of virtual objects, as icons, to choose from, see Figure 3.6[right]. To enable selection without releasing the device, we place the icons at either side of the screen, within reach of the user's thumbs. To visually indicate the icon-object relationships, each icon is connected to its assigned virtual object by a virtual line which is visible on the screen. Each 
virtual object is also highlighted with the same color used for its icon and the connection line.

With touch-based selection it is also possible to move the device so the desired object ends up close to either edge of the screen and then be selected by the user's thumb in a manner similar to the icons-select. However, we have to consider the increased amount of device movement needed for selection, especially for multiple virtual objects. Furthermore, our experience from pilot studies shows that users tend to mostly work at the center of the screen.

The number of icons is optional, however there are some considerations to be made. Having more icons gives a larger virtual object pool to select from but, at the same time, makes it more difficult to see which icon is assigned to each virtual object and can increase the ambiguity. On the other hand having too few icons will reduce the selection options to a level where it will perform no better than the center-select technique. To indicate a convenient number of icons we performed a pilot study where the subjects suggested three icons as they believed more makes it difficult to recognize the icon-virtual object assignments, and less reduces the purpose of the technique which is to provide multiple options.

In case there are more virtual objects in the environment than the number of icons, we choose the virtual objects closest to the screen center, based on their on-screen projections. Furthermore, the order of icon-object assignments is also important: as illustrated in Figure 3.7[a], the crossed connection lines can reduce the perception of the assignments. As illustrated in Figure 3.7[b][c][d], we find the most suitable icon-object assignments as follows: starting from the top icon, the object with the smallest angle between the connection line to the current icon and the screen's up direction is assigned to the current icon. Moving the device changes the relative position of the screen and virtual objects and so the icon assignments must be dynamically updated while hysteresis can be used to make these updates more stable. 


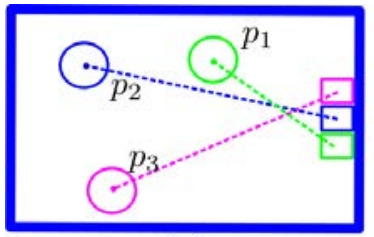

(a)

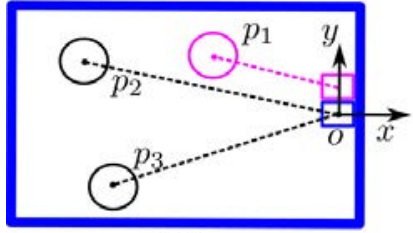

(c)

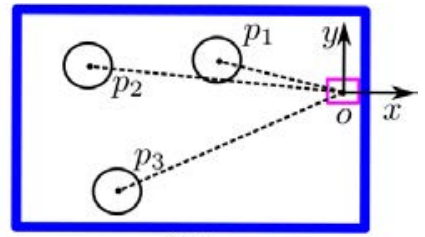

(b)

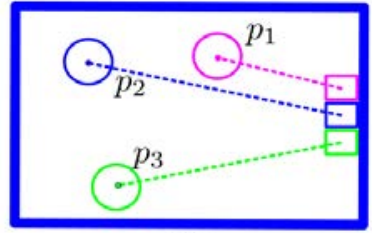

(d)

Figure 3.7: Assignment of virtual objects to selectable icons, in icons-select technique. $p_{1}, p_{2}$ and $p_{3}$ show the projection centers of three virtual objects, on the screen. (a) an example of icon-virtual object crossed lines that will increase the visual ambiguity in object-icon connections; ( $b$, c and d) avoiding cross lines by assigning the icons, one by one, from top to bottom, to the unsigned virtual object with the smallest angle $\angle$ poy . 



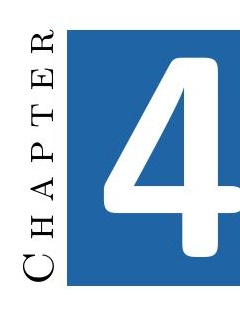

\section{Formal User-based Evaluations}

There are various interaction techniques used for Augmented and Virtual Reality (AR and VR, respectively), with different benefits and disadvantages which make it difficult to choose a specific technique for an application. One way to objectively compare interaction techniques and find their value in different use cases is through formal user-based evaluation. However, quantifying the performance of interaction techniques is difficult without having a well established definition for it [9]. Therefore, defining good performance metrics is a key to being able to compare various techniques in a fair and effective manner. Here, we first present our survey of quality metrics, based on 15 current, important publications on interaction techniques for AR and VR. Then we present design, procedure and outcome of five user-based formal studies. These studies are performed throughout our research, to objectively evaluate our proposed techniques in chapters 2 and 3 , and compare them with the previously existing techniques. The user studies are here categorized based on the papers in which they are presented:

- the first two studies was performed to investigate the effect of user perspective rendering (UPR) on hand-held AR interaction, separately for the selection and pose manipulation of virtual objects, presented in Paper $\mathrm{C}$,

- the third study was performed to investigate the effect of UPR in device posebased pose manipulation (DM). We compared our UPR-based DM with two existing DM techniques, as presented in Paper D, and

- the final set of studies, presented in Paper F, includes two studies: one focused on selection, comparing three device pose-based selection techniques, and the other on manipulation, comparing both, our modified and introduced UPR-based DM 
Table 4.1: List of the interaction techniques and used devices in the reviewed articles.

\begin{tabular}{lll} 
Index & Interaction Techniques & Device \\
\hline P1 & Device-movement \& Touch & Hand-held \\
P2 & Mid-air \& Touch & Touch-table \& HMD \\
P3 & Mid-air \& Device-movement \& Wand & HMD \\
P4 & Mid-air & HMD \\
P5 & Touch & Touch-enabled \\
P6 & Device-movement \& Analog & Hand-held \\
P7 & Device-movement \& Analog & Tangible Hand-held \\
P8 & Mid-air \& Touch & Hand-held \\
P9 & Touch & Touch-enabled \\
P10 & Touch & Touch-enabled \\
P11 & Device-movement \& Touch & Hand-held \\
P12 & Device-movement & Hand-held \\
P13 & Touch & Touch-enabled \\
P14 & Wand \& Analog & Stereoscopic Display \\
P15 & Device-movement & Hand-held
\end{tabular}

techniques.

\subsection{Popular Performance Metrics for Interaction}

To extract the most important performance metrics for evaluation of interaction techniques in virtual environments, we chose 15 published user studies from over a decade (2005-2016) of research. The articles and the conditions by which they were chosen along with a complete presentation of the extracted metrics are presented in Paper E. Various interaction techniques and devices are used in the selected articles, which are listed in Table 4.1. We check, categorize and analyze the formal user studies, and establish and present baseline performance metrics used for evaluation of interaction techniques in VR and AR.

We categorize the metrics, based on how they are used in the studies, into three groups: independent variables, dependent variables, and questionnaire metrics. It is worth mentioning that the same variable can be used in more than one category. Here, however, we present them as they were used in the reviewed publications.

The most common independent variable was the interaction technique. Size of the device, size of the virtual object, transformation type and degrees-of-freedom were also important independent variables. Task completion time was used in almost every publication as dependent variable. Accuracy, measured as the number of errors or misalignment, and success rate, which is measured as either the number of 
successful tasks or the number of failures, were two other important metrics used as dependent variables. From the reviewed publications, 11 presented questionnaires, which mostly used 7-point or 5-point Likert scale for response. The most commonly used questionnaire metrics was the preferred technique (mutually exclusive selection), or how likable each technique is (expressed in Likert scale). Other common questions reflected perceived ease of use or difficulty, perceived accuracy and perceived speed. Less common questionnaire metrics were intuitiveness and comfort.

\subsection{Perspective Effect on Multi-touch Interaction}

To investigate whether DPR or UPR is most beneficial for interacting with virtual objects we designed and performed two user studies where we compare our geometry based UPR technique, described in section 2.1, with the commonly used DPR technique for touch based interaction. Our first study focuses on selection, while the focus of the second study is on pose manipulation.

\subsubsection{Test Environment and Prototype}

The study tests were performed in an area of $2 \times 2$ meters covered by a PhaseSpace LED-based optical motion tracking system for 6 -DoF real-time tracking. We used an off-the-shelf Microsoft Surface Pro 3 tablet PC as a hand-held V-AR device, and used its back camera to capture the live $\mathrm{V}-\mathrm{AR}$ video feed. A 3D printed frame was attached to the tablet, serving as a housing for the LED markers, and their power-source and driver. A pair of safety goggles, also equipped with LED markers was used for head tracking. An image of our prototype device is shown in Figure 4.1.

\subsubsection{Participants and Pre-test Procedure}

The tests were performed in sequence by the same group of subjects, where 14 subjects (4 female and 10 male), all university students with ages in the range of 21 to 37 participated.

Upon arrival, the subjects were asked for their personal information, level of familiarity with the used techniques, and also if they have any physical disabilities or eye condition that would effect the test. Furthermore, the used methods were thoroughly explained to the subjects by a tutor and they were also trained in how to perform the study task. We minimized the impact of learning effects and fatigue by completely balancing the order of the studied techniques within each study, between the subjects. Upon completing each study, we asked the subjects to record their opinion about the used techniques in a post-test questionnaire. 


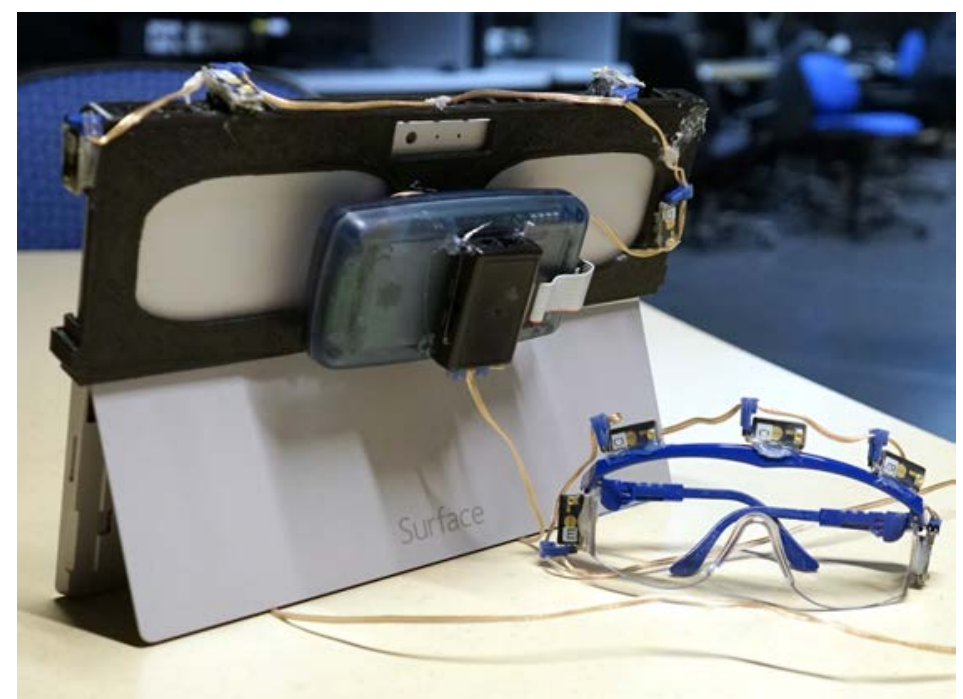

Figure 4.1: The user study prototype device: A tablet PC covered with a 3D printed frame which is the housing for the illuminative LED markers, and the LED power-source and unit driver. A pair of safety goggles attached with illuminative markers.

\subsubsection{Find-and-Select Study}

The first study was designed to investigate whether UPR or DPR is most beneficial to find and select a virtual object (visible only on the screen) in a real environment. We seek to find which perspective is faster and which is more natural and intuitive to find a virtual object and select it using the on-screen touch selection.

\section{Expected Outcome and Hypotheses}

In two separate user studies, Baricevic et al. [5] compared DPR and UPR with their simulator prototype. The first study focused on finding and the second on selecting a virtual object. They reported that in their studies UPR was significantly faster for selection tasks and DPR was preferred by subjects for search tasks. Their results are interesting, however they used a simulation of hand-held UPR presented using a head mounted display (HMD) and a wand, which can potentially be different from the real experience of a hand-held device and touch-based interaction.

We believe selection can be faster in UPR because a virtual object is rendered with its actual size, and is aligned with its correspondence in the real world. Considering that a larger field of view can make finding virtual objects easier, we believe that the dynamic field of view of UPR can be advantageous over the fixed field provided 


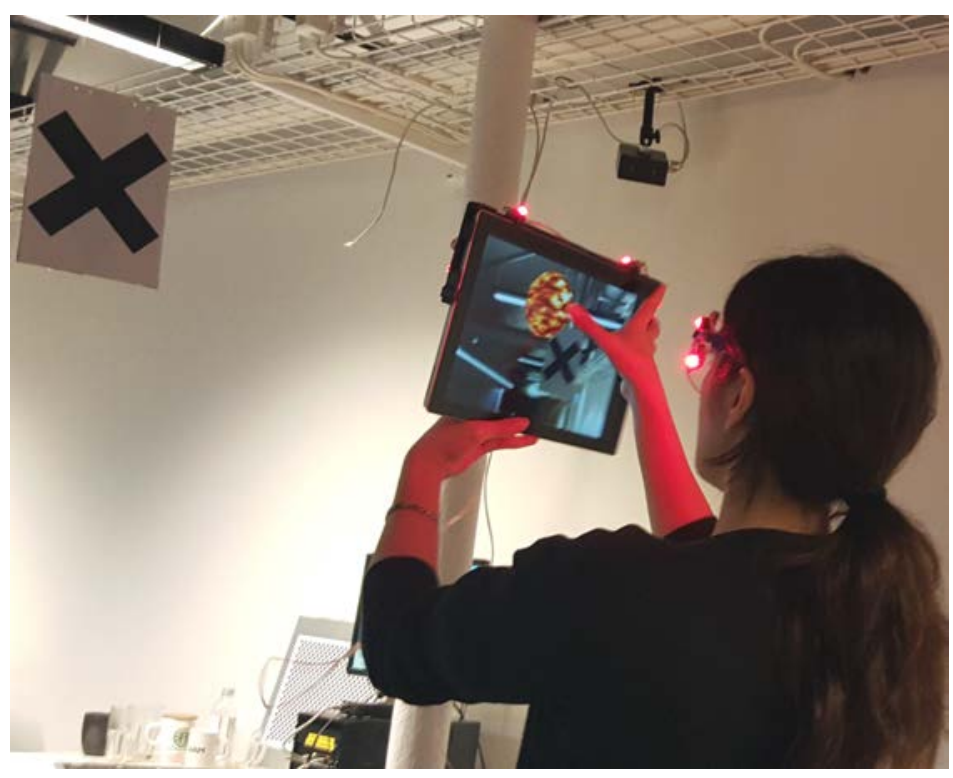

Figure 4.2: A test subject performing the find-and-select test

by DPR. This is, however, dependent on how the subjects take advantage of this dynamic field of view. Overall, due to the difficulty of predicting the outcome of the study, we hypothesized that subjects would be able to have better performance with either of the used methods.

\section{Experimental Design and Procedure}

The study task was to find a virtual sphere, visible only on the screen, in the test environment and select it with a single touch. The task was repeated for thirty virtual spheres and for the two perspectives. The independent variables were the perspectives and the dependent variable was performance in the form of the time it took to complete the task. At the start, test subjects stood in the center of the test area holding the tablet device and wearing the head tracking goggles. Four printed paper signs were placed in the test area, corresponding to the pre-defined positions of the virtual spheres, in the real environment. During the test each sphere appeared upon selection of the last one randomly at one of the four predefined positions. The task completion time was automatically recorded by the system. Fig 4.2 shows a test subject performing the find-and-select test. 
Task completion times for the find-and-select test

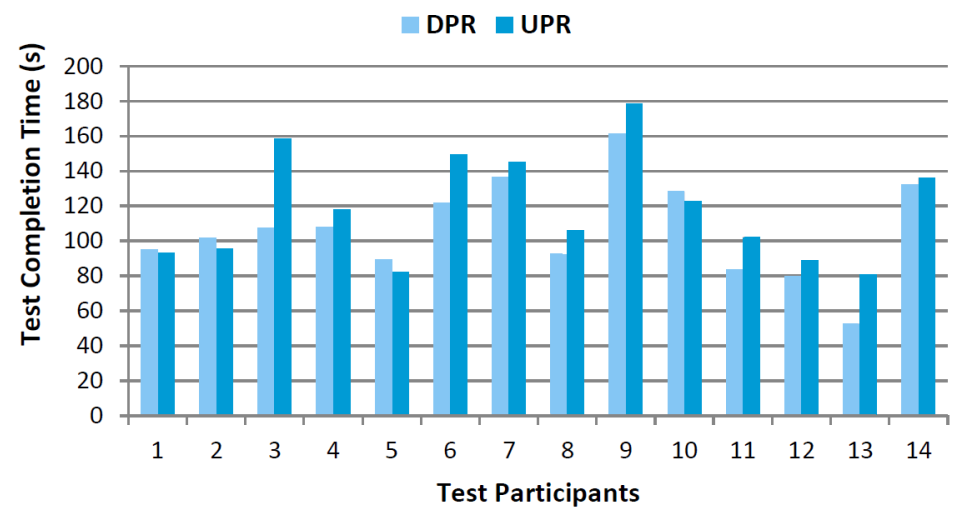

Figure 4.3: The task completion times, of the find-and-select, test for each subject using both DPR and UPR.

Table 4.2: Paired samples statistics for UPR and DPR in the find-and-select test. The mean is the task completion time for all, N, users in seconds.

\begin{tabular}{lllc} 
& Mean & N & Variance \\
\hline DPR & 106.42 & 14 & 776.04 \\
UPR & 118.38 & 14 & 954.28
\end{tabular}

\section{Results}

Table 4.2 and Figure 4.9 show the results from the find-and-select test. Our hypothesis was that the test task may be completed faster in either of UPR or DPR. We used paired two-tail t-test with the significance level of 0.05 where DPR was significantly faster $(\mathrm{t}(14)=2.77, \mathrm{p}=0.016)$. The mean total task completion time also was higher using DPR.

\section{Post-Test Questionnaire}

The goal of the post-test questionnaire was to capture subjective feedback from the participants in the test and the used techniques. We asked about the naturalness and intuitiveness of using each perspective, separately, to find and select virtual objects. The answers were given as "not at all", "a little", "fairly", "quite", and "very much". To capture the similarities, the test subject could vote both methods being as good or bad. For the search task, four subjects stated UPR, six DPR, and four both to be "quite" or "very much" natural and intuitive. For selection, 


\section{Post-test questionnaire results for the find-and-select test}

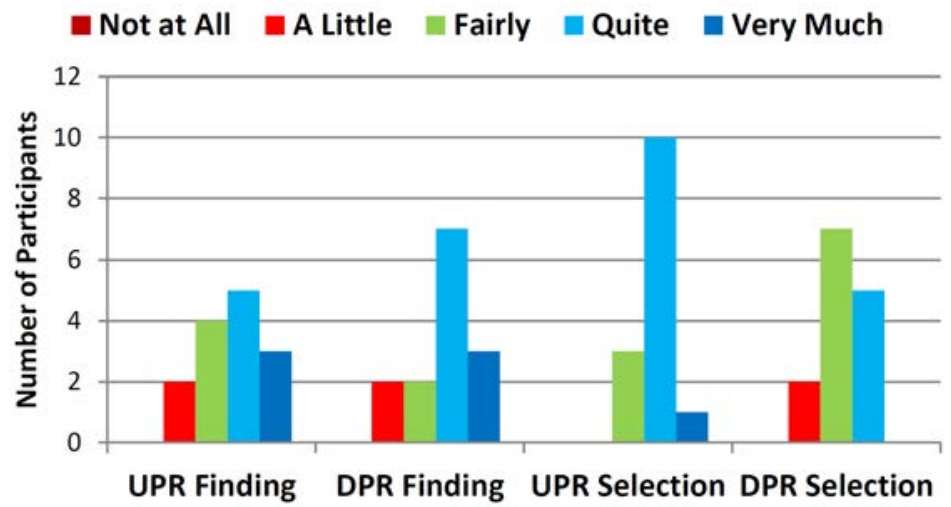

Figure 4.4: The subjects were asked how natural and intuitive they found it to find and select virtual objects using UPR and DPR.

nine subjects found UPR, three DPR, and two both to be "quite" or "very much" natural and intuitive. Figure 4.4 shows the results of the post-test questionnaire.

\section{Discussion}

After completing the study tasks, the subjects stated that the wider view of DPR, on the screen, made it easier to find the virtual objects. By observing the subjects through the test, we understood that they mostly held the device in a distance from their eyes, which resulted in a narrower field of view for UPR compared to the static field of view of the DPR. For selection, the subjects expressed that UPR was easier and more intuitive compared to DPR. This, we believe is due to the rendering of the virtual objects on the user's view direction with UPR, which consequently allows for selection in the view direction. Overall, the subjects did the task significantly faster using DPR. During the test we also observed that the task time was mostly spend to find a virtual object and less to select it. Therefore, we believe the overall results might due to the faster finding the objects with DPR.

\subsubsection{Pose Manipulation Study}

With the second study, we investigated whether using either of DPR or UPR perspectives benefits the rigid transformation of a virtual object in $3 \mathrm{D}$ space, using the multi-touch interaction. The rigid transformation of a 3D virtual object consists of both translation and rotation. In our test multi-finger touch is used to translate and rotate a virtual object in relation to the real world. 
Table 4.3: Paired samples statistics for UPR and DPR in the multi-touch pose manipulation test. The mean is the task completion time for all, N, users in seconds.

\begin{tabular}{llll} 
& Mean & N & Variance \\
\hline DPR & 115.79 & 14 & 2612.61 \\
UPR & 106.11 & 14 & 3435.99
\end{tabular}

\section{Expected Outcome and Hypotheses}

We investigated whether either of UPR or DPR is faster or more natural and intuitive when moving a virtual object using multi-touch on the tablet device. We believe that UPR creates a more realistic and aligned view and therefore better perception of perspective, distance and position of the virtual objects placed in the real environment. We thus hypothesized that test subjects would perform the pose manipulation test faster using UPR.

\section{Experimental Design and Procedure}

We used a 6 DoF docking task to move and align a 3D model of a coffee mug (cursor) with a real coffee mug (target) with both DPR and UPR perspectives and using multi-touch manipulation. The independent variable was the perspective and the dependent variable was performance in the form of the time it took to complete the task.

The real coffee mug was placed on a stand, one meter above the floor, while a virtual model of the same mug was placed, with random orientation, on the floor about 2 meters away. To complete the test each participant had to move the virtual model to the same place as the real one and align its orientation. The touch screen of the tablet device was used to move the virtual object. Each test subject performed the test four times using UPR, and four times DPR. The order of starting the test with either of the perspectives was balanced between all subjects. Figure 4.5 shows a test participant aligning the virtual mug with the real one while performing the test.

\section{Results}

Table 4.3 and Figure 4.10 show the results from the pose manipulation study. Our hypothesis was that the subjects would complete the test faster using UPR. A paired one-tail t-test $\mathrm{t}(14)=0.57, \mathrm{p}=0.29(\mathrm{p}>0.05)$, showed no significant difference between DPR and UPR in performing the pose manipulation test. 


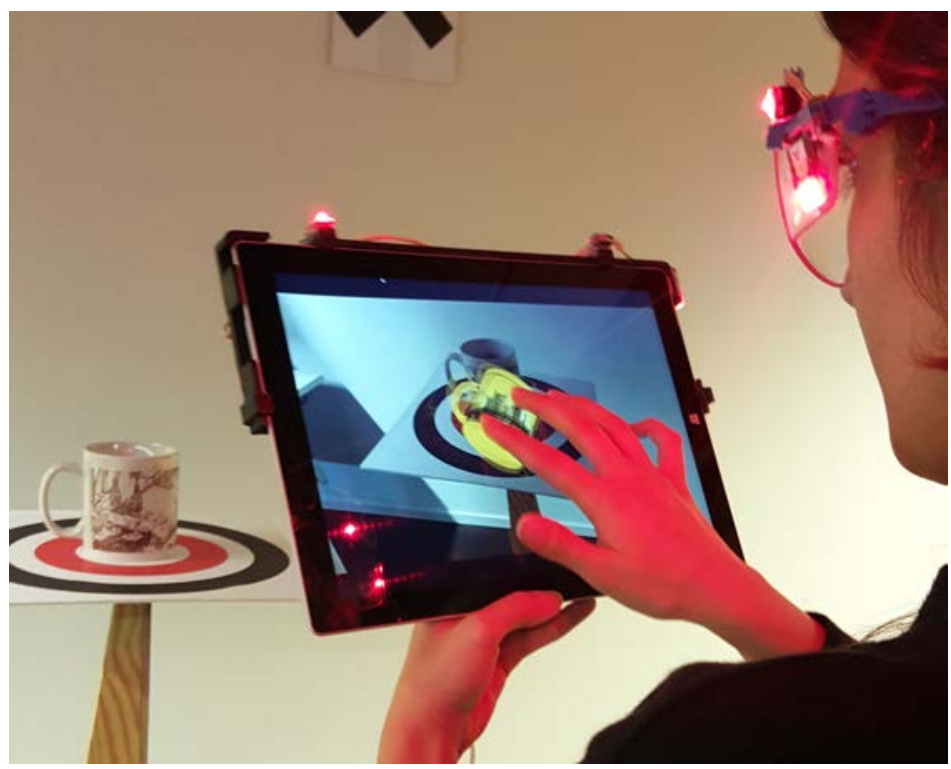

Figure 4.5: A subject performing the pose manipulation test. Here, the test subject is aligning a virtual object with the real corresponding object.

Task completion times for the pose manipulation test

$$
\square \text { DPR } \square \text { UPR }
$$

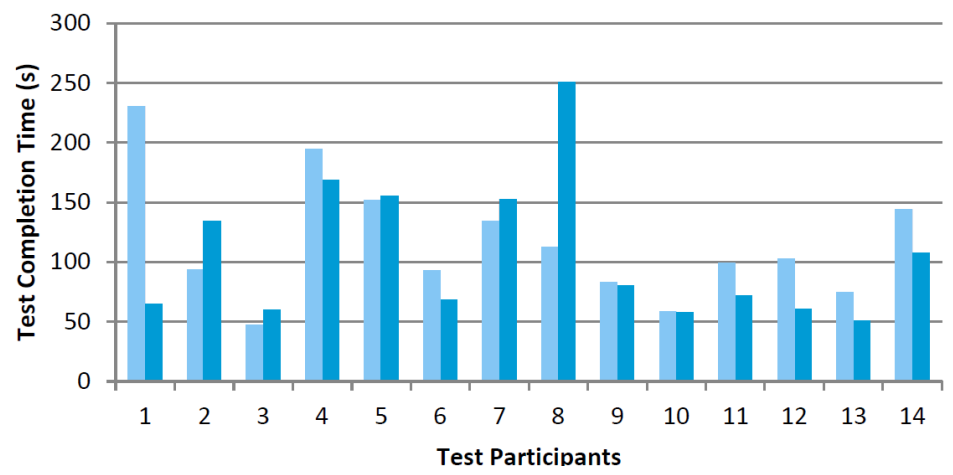

Figure 4.6: The task completion times for each subject for both DPR and UPR. 
Post-test questionnaire results for the pose manipulation test $\square$ Not at All $\square$ A Little $\square$ Fairly $\square$ Quite $\square$ Very Much

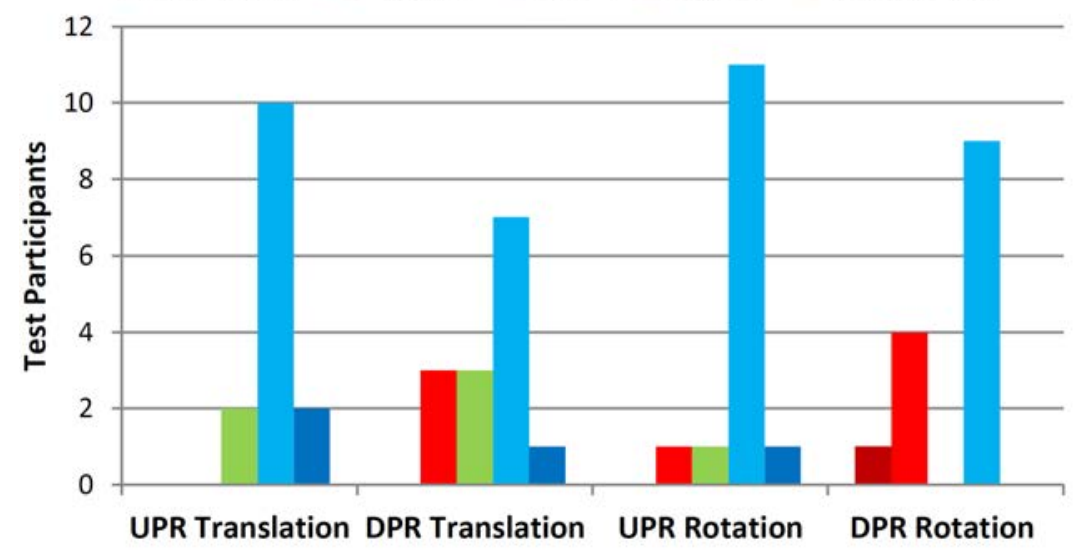

Figure 4.7: The test subjects were asked how natural and intuitive were translating and rotating the virtual object using UPR and DPR.

\section{Post-Test Questionnaire}

The post-test questionnaire explored the subjects opinions about the methods they used during the test. We categorized the answers to "not at all", "a little", "fairly", "quite", and "very much". In case of similarities, the test subjects could answer the same for both methods.

First, the subjects were asked how natural and intuitive either of the perspectives felt for translating the virtual object in 3D space. Six subjects found UPR, two DPR and six both to be "quite" or "very much" natural and intuitive for this. Then we asked for rotating the virtual object during the test. In response five subjects found UPR, two DPR, and seven both perspectives to be "quite" or "very much" natural and intuitive to change orientation of the virtual object. The post-test questionnaire results are shown in Figure. 4.7.

\section{Discussion}

In this study, although more subjects found UPR to be more natural and intuitive, the results showed no significance between two perspectives for the test. During the test, we observed that the test subjects mostly looked through the screen, to complete the task, rather than around it. As discussed in Chapter 2, UPR reduces the misalignment between what is rendered on the screen and the real world that can be seen around the screen. We believe that the small size of our test environment and the near distances of the objects, let the subjects complete 
the task by mostly looking through the screen, which subsequently reduced the benefit of UPR and therefore led to the non-significant result.

\subsection{Perspective Effect on Device Pose-based Ma- nipulation}

In chapter 3, we discussed DM. In section 3.1 we described two existing DPR based DM techniques that we call fix-DPR and relative-DPR. Then, in section 3.2, we introduced our UPR based DM technique, relative-UPR, to reduce the rotation issues with the DPR based techniques. In order to compare the performance of these DPR and UPR based hand-held DM techniques, we conducted a user study.

As also discussed in section 3.1 it is almost impossible to use the fix-DPR method to rotate an object in a distance not reachable by the user. Therefore, we divided the study into two separate tasks: one with a near object which the subject could move around it, and the other with an object that was placed at an unreachable distance. The near test was performed with all three techniques while the far test was performed with relative-DPR and relative-UPR.

\subsubsection{Expected Outcome and Hypotheses}

The expected outcome from the study was based on a preliminary analysis of advantages and drawbacks of each technique. We believe that the main problem with relative-DPR is for yaw and pitch rotations which cause the virtual object to move out of the view. The fix-DPR method solves that problem and keeps the manipulated virtual object visible throughout rotations, however it introduces another issue: moving the object while rotating it. Relative-UPR does not change the view with the orientation of the hand-held device and therefore the virtual object will be visible on the screen as long as it is within the user's view. Furthermore, relative-UPR separates the rotation and translation of the virtual object so it is possible to rotate the virtual object without moving it, unlike fix-DPR.

Based on these observations, we formulated our hypotheses as follows:

H1: Subjects will perform the 3D docking task for a near virtual object faster with relative-UPR compared with relative-DPR.

H2: Subjects will perform the 3D docking task for a near virtual object faster with relative-UPR compared with fix-DPR.

H3: Subjects will perform the 3D docking task for a far virtual object faster with relative-UPR compared with relative-DPR.

We also collected meta information about independent states to allow for further analysis of the study data, complementing the core findings. To avoid increasing 
the problem of multiple comparisons, we did not consider statistical significance for the further analysis and therefore did not include them in the Bonferroni compensations.

\subsubsection{Experimental Design}

The study was designed to compare three DM interaction techniques using a 6 DoF docking task. The task was to move and align a 3D model of a chair (cursor) with a wireframe 3D model of the same chair (target). The independent variables were the interaction techniques and the dependent variable was performance in the form of the time it took to complete the task. The subjects could select and grab the virtual object by touching anywhere on the screen, to avoid selection having an impact on the final results.

For the near test, each subject did twenty dockings per technique, and for the far test 10 dockings per technique. Each docking started with a cursor pose that was randomized between a pre-defined set. This set of poses for the near test was categorized into four modes: translation-only, rotation-only, small-rotation and large-rotation, based on the pose manipulation needed to dock the object and complete the task. These modes were used as meta data for further analysis of the results. We also recorded the number of times the subject released and re-selected the virtual object to correct the perspective as meta information.

\subsubsection{Test Environment and Prototype}

The environment and prototype for this study was the same as our previous study explained in 4.2.1.

\subsubsection{Participants and Procedure}

The study was performed with 15 subjects ( 5 female and 10 male) recruited from the university and with age ranging between 26 and 40 (median 30). To minimize the impact of learning effects the order of used techniques in the test was balanced as far as possible with the 15 subjects for the near test. For the far test 14 subjects from the same group were used to balance the order completely.

We found no physical disability nor uncorrected vision problems that were expected to affect the test. All subjects reported to be experienced with hand-held smart devices, 10 subjects were familiar with AR and 5 reported to be familiar with UPR.

At the start, the DM and other used techniques were thoroughly explained to subjects by a tutor, and they were trained in and practiced each task.

For the near test the subjects started standing in front of a table, above which both the cursor and target appeared. The subjects could gmove around the table 


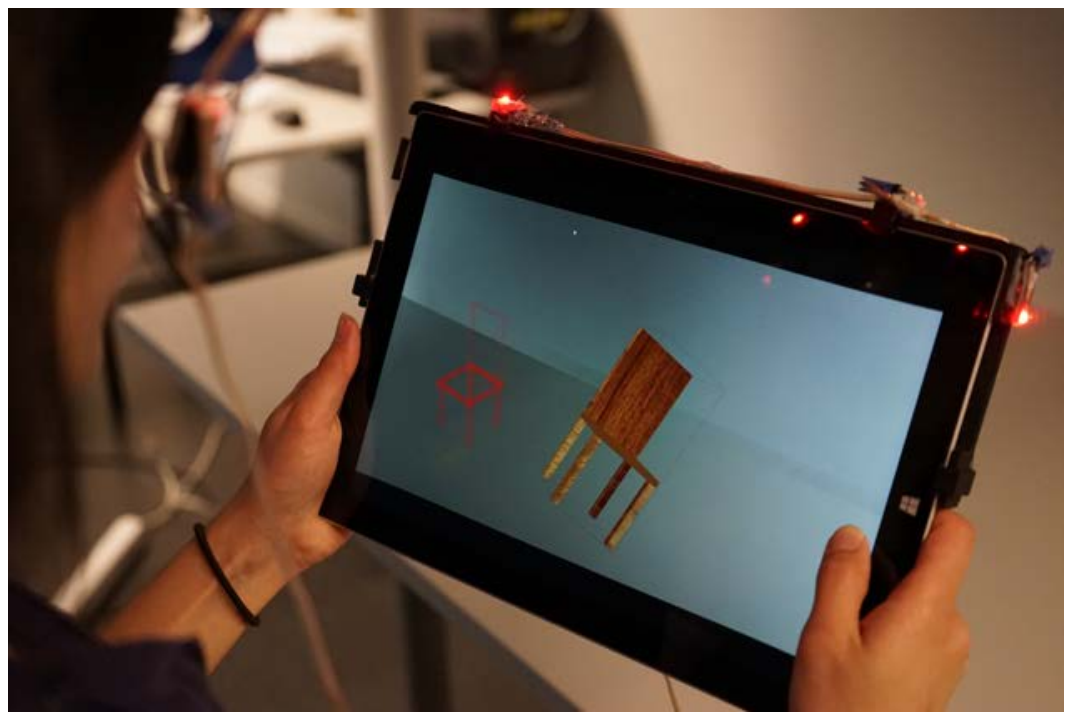

Figure 4.8: A test participant performing the 3D docking task for a near virtual object.

during the test to see the virtual object from different angles. For the far test the cursor and target were presented at a distance so that the subjects could not move around them. Figure 4.8 shows a subject performing the near 3D docking task. After performing all tasks the subjects completed a questionnaire to capture their overall preference for the used techniques.

\subsubsection{Results}

For the near test, we used a Kolmogorov-Smirnov test to verify that the performance data were normally distributed. A single-factor repeated measures ANOVA, at $\mathrm{p}<0.05$, was conducted to compare the effect of using different DM techniques on the mean task completion time. Post hoc test with a Bonferroni correction was used in case of statistical significance. the Greenhouse-Geisser correction was applied if the sphericity condition was violated.

The data from the far test were analysed with a one tail t-test to compare the task completion times. The direction of the one-tail test was defined based on our previously made hypothesis. 
Table 4.4: Descriptive statistics for the near and far test. The mean is the task completion time for all $\mathrm{N}$ users in seconds.

\begin{tabular}{|c|c|c|c|}
\hline Technique & Mean & SD & $\mathrm{N}$ \\
\hline Relative-DPR & 17.884 & 7.014 & 15 \\
\hline$\stackrel{Ð}{\circlearrowright}$ Fix-DPR & 13.86 & 4.245 & 15 \\
\hline Z Relative-UPR & 11.745 & 4.576 & 15 \\
\hline : Relative-DPR & 16.719 & 6.457 & 14 \\
\hline 项 Relative-UPR & 10.467 & 3.138 & 14 \\
\hline
\end{tabular}

\section{Near Test}

Table 4.4(top) shows the descriptive statistics of the near test. The task completion time differed significantly between the used techniques $(\mathrm{F}(2,13)=7.739, \mathrm{p}=0.006)$. Post hoc tests revealed that the mean task completion time for relative-UPR was significantly faster than relative-DPR $(p=0.004)$. There was no significant difference between the mean task completion time for relative-UPR and fix-DPR $(\mathrm{p}=0.092)$.

The results support $\mathrm{H} 1$ which stated that the relative-UPR will be faster than relative-DPR, so H1 is accepted. However, our second hypothesis, H2, is not confirmed, since we did not find a statistically significant difference between the task completion time for fix-DPR and relative-UPR.

\section{Far Test}

The descriptive statistics of the far test are shown in Table 4.4(bottom). The one tail t-test $\left(\mathrm{t}(13)=4.068, \mathrm{p}=7 \times 10^{-4}\right)$ shows statistical significance between the task completion time for relative-DPR $(\mathrm{M}=16.719, \mathrm{SD}=6.275)$ and relative-UPR $(\mathrm{M}=10.467, \mathrm{SD}=4.0146)$, in the favor of relative-UPR.

The result supports H3 which stated that relative-UPR is significantly faster than relative-DPR when interacting with a far virtual object.

\section{Further Analysis}

The mean task completion times of each subject, separately for each method, from the near and far tests are shown in Figures 4.9 and 4.10, respectively.

For further analysis for the data, the same statistical methods were applied as for the hypotheses falsification process described earlier, but here separately for each mode (translation-only, rotation-only, small-rotation and large-rotation) of the near test. Analyzing the task completion time for the translation-only mode showed that the difference seen could have arisen by chance $(\mathrm{p}=0.127)$. That is understandable considering that translation mapping is mostly similar among the 
Task completion times for the near test

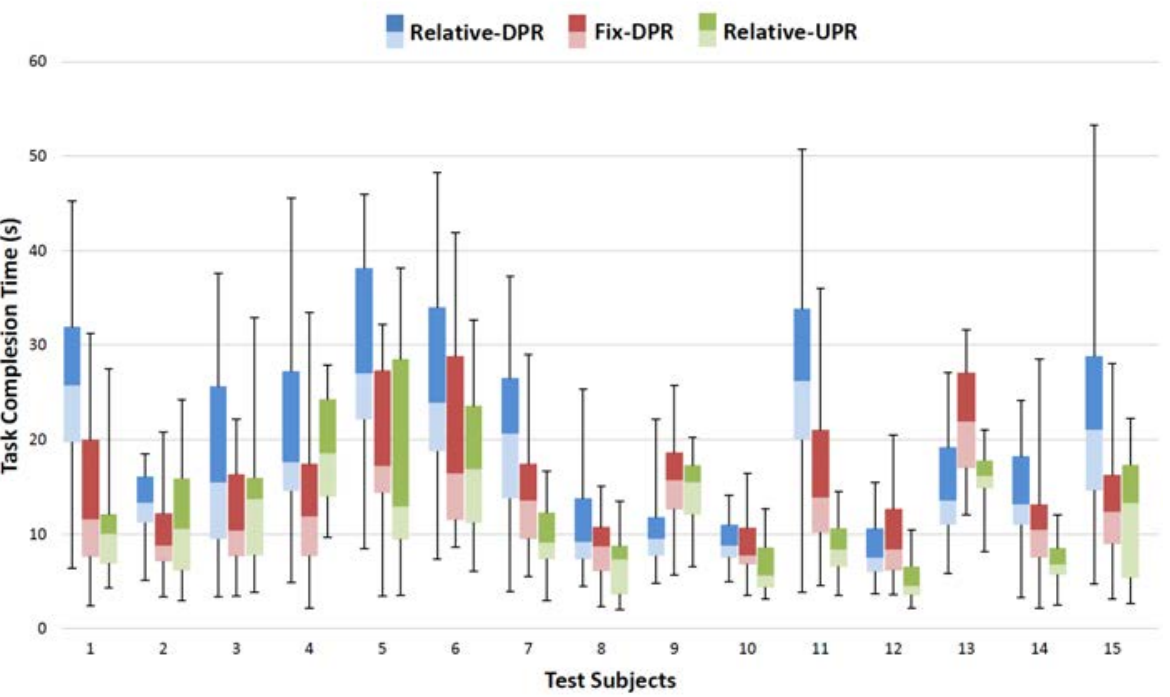

Figure 4.9: Each candle shows the min, median and max times for each participant. Quartiles 2 and 3 are indicated with lighter and darker colors, respectively.

Task completion times for the far test

Relative-DPR $\quad$ Relative-UPR

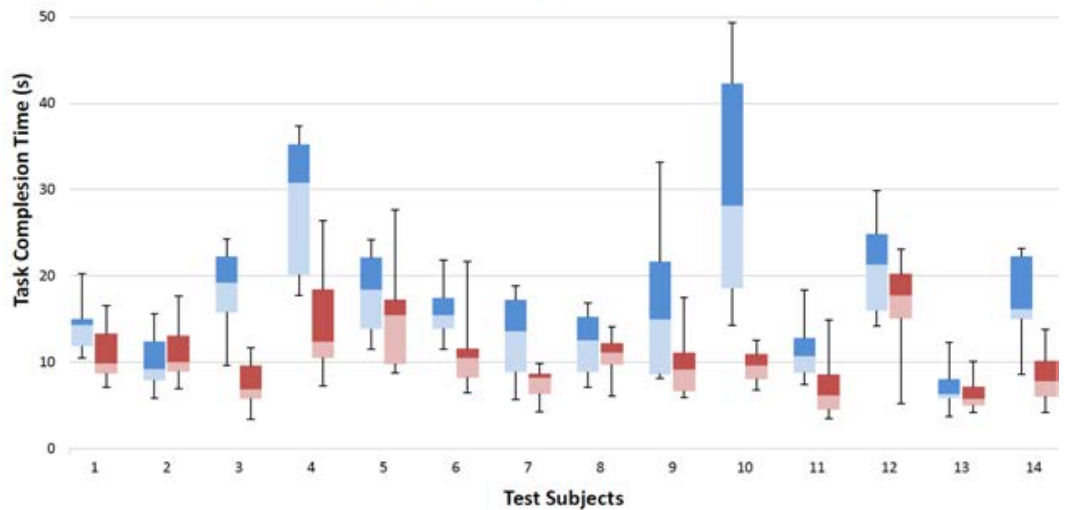

Figure 4.10: Each candle shows the min, median and max times for each participant. Quartiles 2 and 3 are indicated with lighter and darker colors, respectively. 
Table 4.5: Descriptive statistics of the number of times the subject released the virtual object to change pose during the docking task. The mean is of the number of pose changes over all, $\mathrm{N}$, users.

\begin{tabular}{|c|c|c|c|}
\hline Technique & Mean & $\mathrm{SD}$ & $\mathrm{N}$ \\
\hline Relative-DPR & 113.6 & 28.493 & 15 \\
\hline שี Fix-DPR & 55.73 & 6.974 & 15 \\
\hline Z Relative-UPR & 41.467 & 14.141 & 15 \\
\hline تี Relative-DPR & 76.857 & 24.844 & 14 \\
\hline I Relative-UPR & 33.786 & 12.192 & 14 \\
\hline
\end{tabular}

compared techniques. The difference in mean task completion time for the rotationonly mode is unlikely to have arisen by chance: the data indicate that relative-UPR is faster than relative-DPR $(\mathrm{p}=0.003)$ and that relative-UPR is faster than fix-DPR $(\mathrm{p}=0.037)$. The mean task completion time differences for the small-rotation and large-rotation modes is less likely to have arisen by chance between relative-DPR and relative UPR. The data indicate that relative-UPR is faster than relative-DPR for small-rotation $(p=0.004)$ and large-rotation $(p=0.024)$ modes. However, the differences between fix-DPR and relative-UPR are not unprobable to have arisen by chance for both the small-rotation $(\mathrm{p}=0.526)$ and large-rotation $(\mathrm{p}=0.234)$ modes.

The number of times the subject released the virtual object to change pose was also compared for both the near and far tests, shown in Table 4.6. The data show a strong indication that relative-UPR may require less pose changes than both relative-DPR $\left(\mathrm{p}=3 \times 10^{-7}\right)$ and fix-DPR $(\mathrm{p}=0.012)$ in near interaction as well as compared to relative-DPR in far interaction $\left(\mathrm{p}=6 \times 10^{-6}\right)$.

\section{Post-Test Questionnaire}

The post experiment questionnaire was designed to capture the overall preference of the subjects. The questions and answers are listed in Figure 4.11. We asked the subjects for their preferred technique for rotating and for moving a virtual object. 10 subjects preferred relative-UPR, 4 fix-DPR, and 1 relative-DPR to rotate a near virtual object. To translate a near virtual object, 7 subjects preferred relative-UPR, 8 fix-DPR, and there was no vote for relative-DPR. For a far virtual object, 12 subjects preferred relative-UPR over relative-DPR for both translation and rotation.

The subjects were also asked which technique they believe was easier to learn and to use. 9 subjects found relative-UPR, 6 fix-DPR, and none relative-DPR to be easier than the other techniques when performing the near test. For the far test, 11 subjects chose relative-UPR and 3 relative-DPR to be the easiest technique.

Finally we asked which technique felt more natural and intuitive during the test. 10 subjects chose relative-UPR and 5 fix-DPR to be more natural for near object 


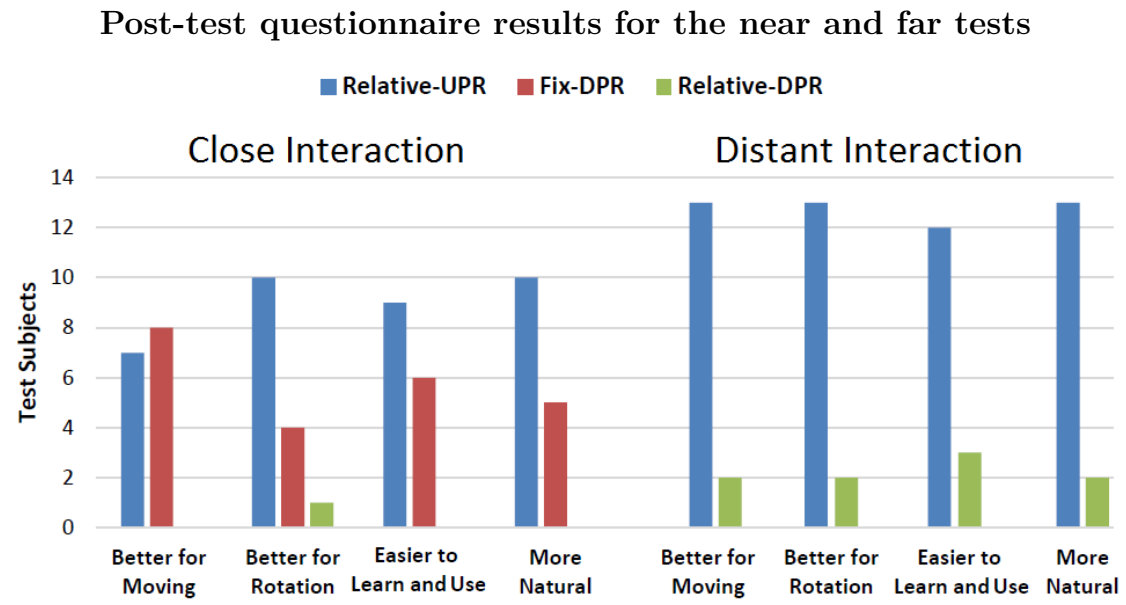

Figure 4.11: The overall preference of the subjects separately for the near and far tests.

manipulation, and 12 chose relative-UPR over relative-DPR to be more natural and intuitive for manipulation of a far object.

\subsubsection{Discussion}

The result from the rotation-only task analysis for the near test agrees with our argument that relative-UPR resolves the rotation problem with the fix-DPR as discussed in section 3.2. This is also reflected in the overall mean task completion times listed in table 4.4 although these differences did not yield statistical significance, as reported in section 4.3.5. In the near test the subjects could easily move around the virtual object, which we believe reduced the negative effect of rotation using the fix-DPR and consequently led to the non-significant result.

The number of times the subject released the virtual object to change pose indicates that relative-UPR requires less such pose changes than the other techniques. Using relative-DPR, subjects needed to divide a large rotation into a sequential of small ones to keep the virtual object visible on the screen. With fix-DPR, to avoid moving the tablet on long trajectories during a large rotation, it was also necessary to divide the rotation into smaller ones. Relative-UPR, however, keeps the virtual object on the screen during rotation and therefore allows for larger rotations with a single motion. Also, we believe that more subjects preferred relative-UPR rotation for both near and far tests for the same reason, because of the rotation issues in DPR.

The number of subjects that preferred fix-DPR for translation, of a near object, were similar but higher than the relative-UPR. We believe this is caused by the 
perspective effect that prevents relative-UPR from keeping the translated object at the same spot, as discussed in section 3.2.

\subsection{UPR Device-based Interaction Evaluation}

In hand-held AR, as discussed in chapter 3, the device itself can be used as a wand to enable a direct $3 \mathrm{D}$ interaction with the virtual world. To compare the performance of device pose-based interaction techniques, we designed and performed two user studies, one for selection and the other for pose manipulation, where our assessment of the performance was in terms of speed, fatigue and accuracy.

We discussed the device pose-based selection techniques in section 3.3, where we presented a modified version of the center-select technique and introduced the icons-select technique. With the first study we compared the performance of these selection techniques against each other and also against the common touch-based selection.

We introduced relative-UPR DM technique in section 3.2. This approach was designed to overcome the rotation issues with the existing DPR based DM techniques, discussed in 3.1, and was compared to the DPR-based techniques in a user study, presented in section 4.3. Furthermore, we introduced another DM technique, fix-UPR, in section 3.2 to resolve the translation issue with relative-UPR discussed in section 3.1. With the second study we compared the performance of our UPR-based DM techniques, relative-UPR and fix-UPR, for manipulation tasks.

\subsubsection{Test Environment and Prototype}

The environment and prototype for both studies was identical to our previous study explained in 4.2.1.

\subsubsection{Participants and General Procedure}

Both studies were performed in sequence by the same group of 18 test subjects, who were recruited from the university ( 5 female and 13 male) with age ranging from 22 to 36 (median 30). The order of the studied techniques were completely balanced within each study between the 18 subjects, to minimize the impact of learning effects and fatigue.

Before the test, each subject was asked about their level of experience with handheld V-AR, and also possible disabilities that were expected to affect the test. Furthermore, a tutor thoroughly described UPR V-AR, DM and the other techniques used in the study and the subjects were trained each test. Each subject first performed the selection study followed by a questionnaire, and then the manipulation study followed by another questionnaire. 


\subsubsection{Selection Study}

The aim of the selection study was to compare the user's performance with different selection methods, center-select, icons-select and touch-select, in terms of speed, fatigue and accuracy. Also, therefore, no manipulation was included in this study.

\section{Expected Outcome and Hypotheses}

We observed in our pilot tests that touch-select can be difficult to use, since subjects need to hold the device with one hand and select the object on the screen with the other hand which consequently results in finger occlusion. Icons-select requires less movement of the device between multiple selections, since the virtual objects can be chosen from a list. The accuracy of the icons-select, on the other hand, may be lessened by the confusion due to the virtual object-icon connections that are dynamically changed by movements of the device. We expect a higher level of accuracy with touch-select, due to the direct connection between touch action and selected virtual object. These observations are formulated into the following hypotheses:

H1: Subjects will perform the selection task faster with icons-select and centerselect compared with touch-select.

H2: Subjects will move the device less with icons-select compared with touch-select and center-select.

H3: Subjects will make less incorrect selections with touch-select and center-select compared with icons-select.

\section{Design and Procedure}

To simulate a crowded scene, including object occlusions, we designed a three dimensional array of virtual cubes that were rendered through the AR display. The task for the subjects was to select, one-by-one, a randomly highlighted one (Figure 4.12). The performance metric was recorded as the time to complete the task (speed), the length of the trajectory that the device moved (representing fatigue), and the number of erroneous selections (accuracy). These were considered the dependent variables, and the selection techniques were the independent variables.

We used 27 virtual cubes, of $5 \times 5 \times 5$ centimeters, which were placed in $3 \times 3 \times 3$ cube formation with 40 centimeters distance between two neighboring cubes. To complete the task, the subjects had to select 30 virtual cubes, where the task was done once for each selection technique, and the order of techniques was perfectly balanced within the group. Three randomized predefined sets, one for each technique, determined the order of highlighting. These sets were also balanced with respect to the overall positions and distances between the cubes to select. 


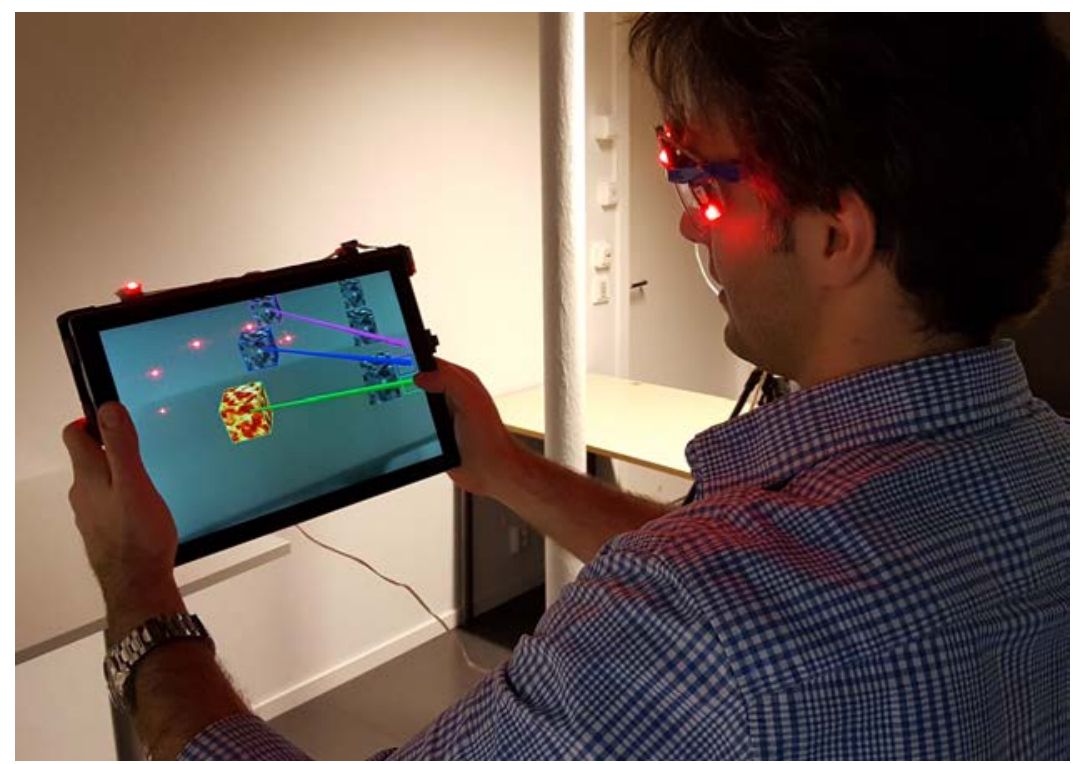

Figure 4.12: The selection test, here performed with icons-select technique.

After completing the test the subjects were asked to express their preferences through a post-experiment questionnaire.

\section{Results}

Descriptive statistics from the study are presented in table 4.6. The recorded data were analyzed with repeated measures ANOVA, with statistical significance at $\mathrm{p}<0.05$, separately for the task completion time, the amount of device movement, and the number of erroneous selections. The Kolmogorov-Smirnov test verified that the data were normally distributed, and Mauchly's test indicated that the sphericity assumption was not violated.

The task completion time differed significantly between the selection techniques, Wilk's Lambda $=0.481, \mathrm{~F}(2,16)=8.615, \mathrm{p}=0.003$. Post hoc tests, with Bonferroni correction, revealed that the mean task completion times for touch-select and center-select were significantly faster than for icons-select, $p=0.031$ and $p=0.002$, respectively. We did not find any significant difference between touch-select and center-select $(\mathrm{p} \approx 1.0)$.

There was a significant effect of the selection technique on the amount of device movement to complete the task, Wilk's Lambda $=0.548, \mathrm{~F}(2,16)=6.6, \mathrm{p}=0.008$. Post hoc test, with Bonferroni correction, revealed that the distance was significantly 
Table 4.6: Descriptive statistics of the selection test. The mean time is the task completion time for all, $\mathrm{N}$, users in seconds. The mean distance is the amount of device movement to complete the task, in meters. The mean error is the number of erroneous selection during the test.

\begin{tabular}{lllll} 
Measure & Technique & Mean & SD & N \\
\hline \multirow{3}{*}{ Time } & Touch-select & 64,762 & 23,951 & 18 \\
& Center-select & 63,461 & 18,396 & 18 \\
& Icons-select & 77,331 & 18,787 & 18 \\
\hline \multirow{3}{*}{ Distance } & Touch-select & 7,916 & 3,534 & 18 \\
& Center-select & 7,486 & 2,294 & 18 \\
& Icons-select & 5,783 & 1,288 & 18 \\
\hline \multirow{3}{*}{ Error } & Touch-select & 4,67 & 3,581 & 18 \\
& Center-select & 3,78 & 2,981 & 18 \\
& Icons-select & 4,61 & 2,477 & 18
\end{tabular}

shorter with icons-select, compared to both touch-select $(\mathrm{p}=0.032)$ and center-select $(\mathrm{p}=0.011)$. The touch-select and center-select did not differ significantly $(\mathrm{p} \approx 1.0)$.

We could not find any significant effect of the selection techniques on the number of wrong selections, Wilk's Lambda $=0.916, \mathrm{~F}(2,16)=0.0 .729, \mathrm{p}=0.498$.

Thus, the results do not support H1, which stated that icons-select will be faster than the other techniques. They do, however, support H2, that predicted that the required device movement for icons-select would be less than with the other techniques. Also, the results do not support H3, stating that the number of incorrect selections would be less using touch-select and center-select compared to icons-select.

\section{Post-test Questionnaire}

The questions and answers from the post-test questionnaire, designed to capture the preferences of the subjects, are listed in Figure 4.13. The subjects were first asked how easy each technique was to learn, where $61 \%$ of them expressed icons-select, $88 \%$ center-select, and 95\% touch-select to be somewhat or very easy to learn. The subjects were then asked how easy each technique was to use (physically). 50\% chose icons-select, $94 \%$ center-select, and $61 \%$ touch-select to be somewhat or very easy to use. When asked about the amount of tiredness caused by using each method, $45 \%$ of the subjects chose icons-select, $23 \%$ center-select, and $67 \%$ touchselect to be somewhat or very tiring. Then the subjects were asked how natural and intuitive each technique felt. $50 \%$ believed icons-select, $89 \%$ center-select, and $72 \%$ touch-select to be somewhat or very natural and intuitive. Finally, the subjects revealed their overall preferred selection technique, where $61 \%$ of the subjects chose center-select, $28 \%$ touch-select, and the remainder icons-select $(11 \%)$. 
Post-test questionnaire results for the selection test

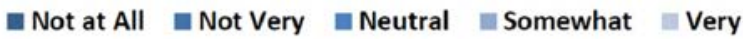

The technique was easy to learn.

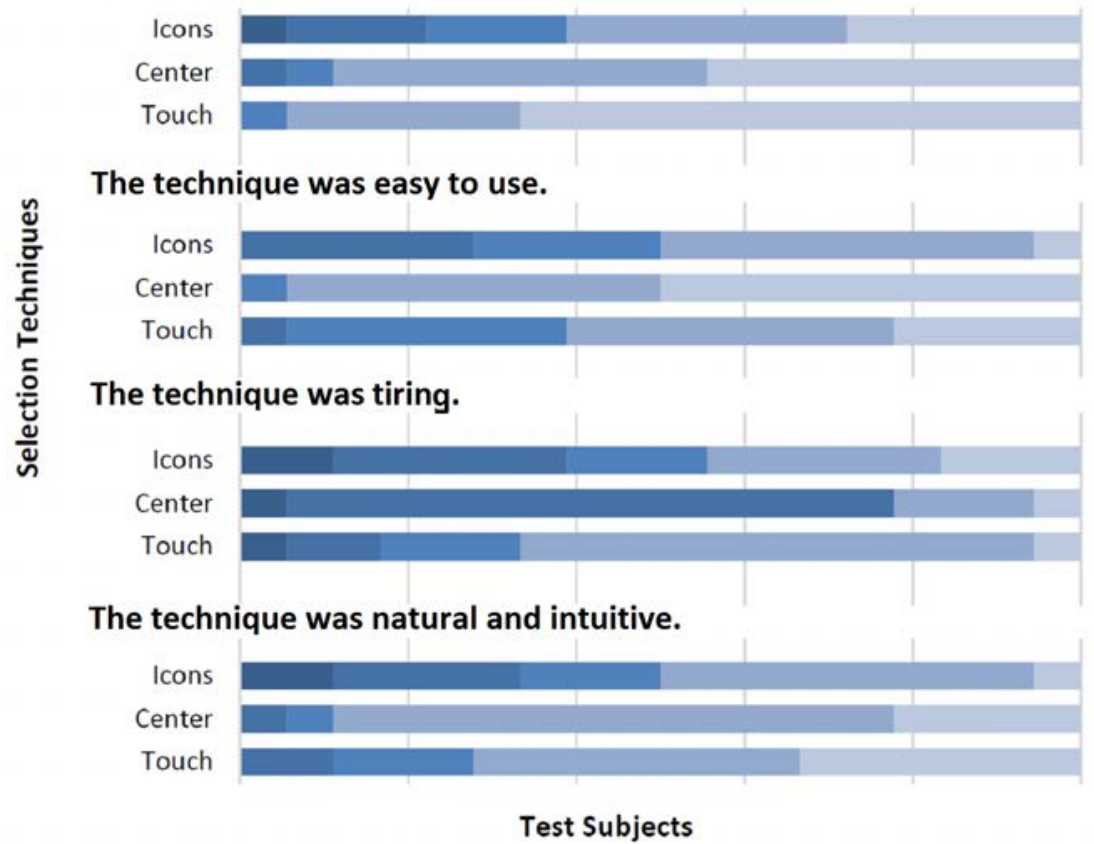

Figure 4.13: The answers show overall preference of the subjects after performing the selection test, separately for each technique.

\section{Discussion}

The results reveal that icons-select took significantly more time to complete the task compared to other techniques. We believe that having multiple selection options cost additional time for the test subjects to find the association between the icon and the desired virtual object, which is further increased when the icon-object assignments change rapidly. This is more of a problem with many virtual objects at close proximity, but decreased by adding hysteresis, which on the other hand leads to a less intuitive order of icon-object assignments. This may also explain why more subjects described icons-select as less easy to learn and use compared with touch-select and center-select.

Touch-select was chosen by the subjects to be the most tiring technique. We believe this is likely to be because the users need to hold the device with one hand during the test. The statistics revealed that the amount of device movement with 
icons-select was significantly less than the other techniques, which seems in contrast with the subjects' indication of the method being more tiring than center-select. This, we believe, can be explained by the longer mean task time with icons-select that overall led to more fatigue.

We predicted that the icons-select would cause more errors, by providing multiple selection choices. However, the results did not yield any statistically significant difference between the techniques. In our opinion this can be explained by considering the longer task time with icons-select, which can mean that the subjects took more time to carefully choose the correct icon, and thus did not make more mistakes. This also agrees with some observations during the tests.

\subsubsection{Manipulation Study}

The manipulation study was designed to evaluate and compare the performance of our introduced DM techniques; relative-UPR, which resolves rotation issues of DPR-based DM techniques is compared with fix-UPR, that aims to resolve the translation issue of relative-UPR, both techniques are discussed in section 3.2.

\section{Expected Outcome and Hypotheses}

Based on our pilot trials and technical analysis of both UPR-based DM techniques, we believe that fix-UPR resolves the translation issue found with relate-UPR. Fixing the virtual object to the view consistently keeps the virtual object visible on the screen, unlike relative-UPR. Therefore, we believe, with relative-UPR the users need to release the virtual object, manually correct the view, and re-grab the object, during the manipulation. Thus, fix-UPR will lead to faster manipulation and require less movement of the device. These observations are formulated into hypotheses as follows:

H1: Subjects will perform the manipulation task faster with fix-UPR compared with relative-UPR.

H2: Subjects will move the device less with fix-UPR compared with relative-UPR.

H3: Subjects will release and grab virtual objects more frequently with fix-UPR compared with relative-UPR.

\section{Design and Procedure}

The two UPR-based DM techniques (relative-UPR and fix-UPR) were compared using the task to complete a nine piece puzzle, by placing the pieces at their correct position, with their correct orientation. The independent variable was the interaction techniques. The dependent variables were performance metrics in the form of task completion time, the length of the trajectory that the device was moved, and the number of re-grabs of each puzzle piece before it is docked. 


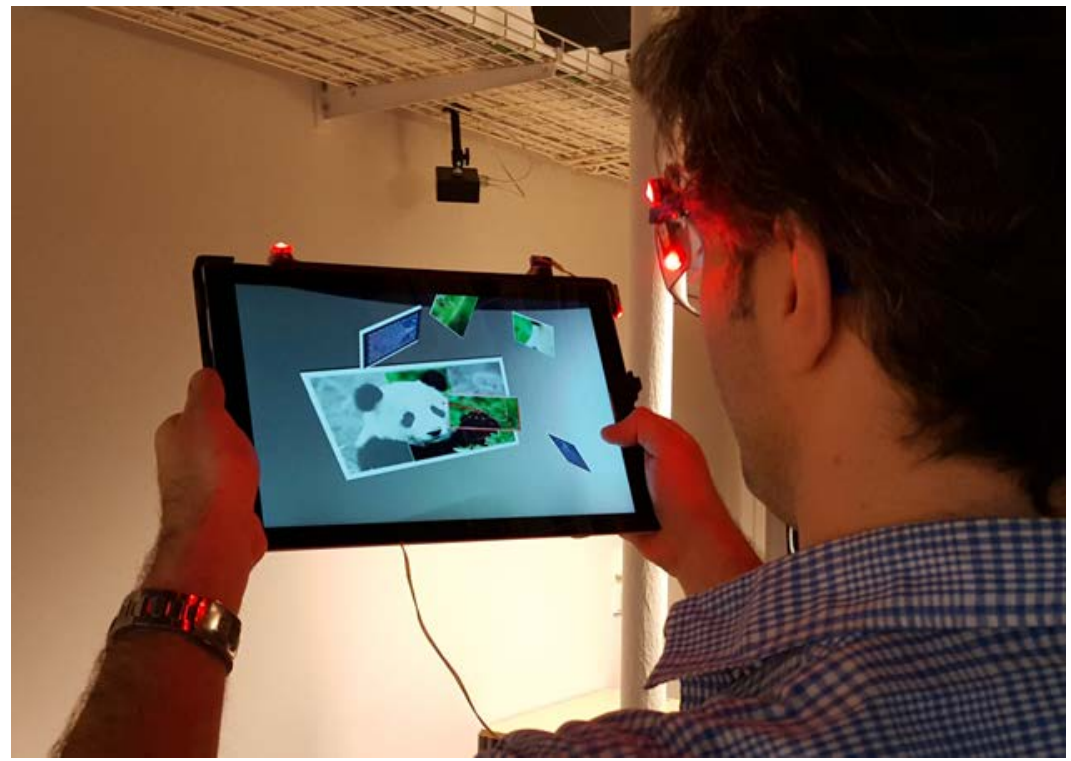

Figure 4.14: A subject is solving the virtual puzzle of the manipulation test.

The nine puzzle pieces had to be moved from a random position onto the puzzle board (in gray scale), to complete the task, see Figure 4.14. To prevent the puzzlesolving skills of the subjects from effecting the results, the puzzle was chosen to be very simple. Finding the correct orientation was also facilitated by the rectangular design of the pieces. The subjects solved the puzzle once with relative-UPR and once with fix-UPR, with the order balanced between the subjects. Based on a pilot study center-select was the preferred selection technique, and thus used for picking the pieces.

The test was followed by a post-test questionnaire where the subjects were asked to record their overall preferences for the used techniques.

\section{Results}

The descriptive statistics of the results from the manipulation test are presented in table 4.7. Separate repeated measures ANOVAs, with statistical significance at $\mathrm{p}<0.05$, were done on the task completion time in seconds, the device movement in meters, and the number of virtual object re-grabs. The normal distribution of the data has been verified by the Kolmogorov-Smirnov test and the sphericity assumption has been confirmed for all ANOVAs.

The analysis indicates that the manipulation technique significantly affect the task completion time, Wilk's Lambda $=0.645, \mathrm{~F}(1,17)=9.369, \mathrm{p}=0.007$, in favor of 
Table 4.7: Descriptive statistics of the manipulation test. The mean time is the task completion time for all $(\mathrm{N})$ users in seconds. The mean distance is the amount of device movement to complete the task, in meters. The re-grab measure is the number of virtual object re-selects to complete the task.

\begin{tabular}{lllll} 
Measure & Technique & Mean & SD & N \\
\hline \multirow{2}{*}{ Time } & Relative-UPR & 237.803 & 103.288 & 18 \\
& Fix-UPR & 187.578 & 84.557 & 18 \\
\hline \multirow{2}{*}{ Distance } & Relative-UPR & 22.809 & 6.638 & 18 \\
& Fix-UPR & 15.17 & 7.203 & 18 \\
\hline \multirow{2}{*}{ Re-grab } & Relative-UPR & 84.67 & 37.674 & 18 \\
& Fix-UPR & 59.11 & 29.846 & 18
\end{tabular}

fix-UPR. There was a significant effect of the manipulation technique on the length of the device movement, Wilk's Lambda $=0.243, \mathrm{~F}(1,17)=53.078, \mathrm{p}=10^{-6}$, in favor of fix-UPR. The number of re-grabs for each puzzle piece was significantly different between the techniques, Wilk's Lambda $=0.597, \mathrm{~F}(1,17)=11.480, \mathrm{p}=0.003$, also in favor of fix-UPR.

The results support all three hypotheses: the subjects performed the experiment faster with fix-UPR than relative-UPR, with fix-UPR the subjects had to move the device less than with relative-UPR and the number of re-grabs performed by the subjects to complete the task was less with fix-UPR than with relative-UPR.

\section{Post-test Questionnaire}

The questions and answers from the post manipulation experiment questionnaire are presented in Figure 4.15. A total of $94 \%$ of the subjects found fix-UPR and $83 \%$ relative-UPR to be somewhat or very easy to learn. When asked about ease of use $94 \%$ found fix-UPR and $83 \%$ relative-UPR to be somewhat or very easy to use (physically). $33 \%$ of the subjects expressed fix-UPR and $61 \%$ relative-UPR to be somewhat or very tiring to use. $89 \%$ of the subjects found fix-UPR and $50 \%$ relative-UPR to be somewhat or very natural and intuitive. Finally the subjects were asked which technique they preferred as a manipulation technique, where $83 \%$ chose fix-UPR and the rest relative-UPR (17\%).

\section{Discussion}

The statistical results indicate that fix-UPR was faster than relative-UPR, and also required significantly less device movement to complete the puzzle test. We believe the reason is that with fix-UPR the manipulated virtual object is kept consistently in the view while with relative-UPR the subjects are required to realign the manipulated object and the view. This also explains why with fix-UPR we saw 
Post-test questionnaire results for the manipulation test Not at All Not Very Neutral $=$ Somewhat $=$ Very

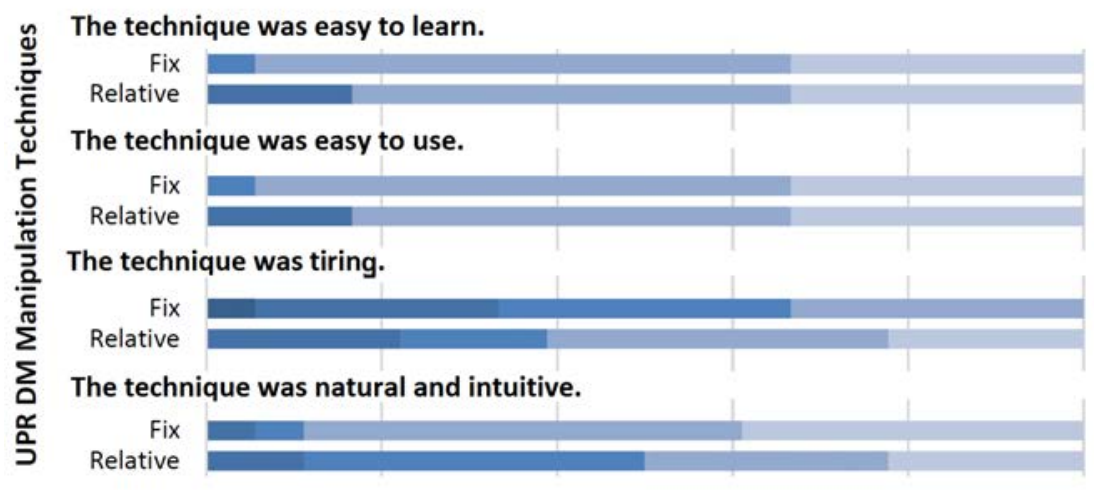

Test Subjects

Figure 4.15: The answers show overall preference of the subjects after performing the manipulation test, separately for each technique

significantly less re-grabbing of the virtual objects. The subjects' preferences also agreed with the statistical results indicating that fix-UPR was easier to learn and use, also less tiring and more natural and intuitive. 


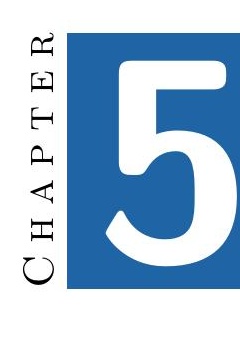

\section{Concluding remarks}

This thesis presents an overview of our research on video see-through hand-held Augmented Reality (AR), with the contributions mostly focused on rendering, interaction, and our user evaluations, presented in chapters 2, 3, and 4 respectively. Here we will summarize our contributions along with some of the conclusions from the results of our user evaluations.

\subsection{User Perspective Augmented Reality}

Previous approaches to user perspective rendering (UPR) for hand-held AR, mostly use homography which depends on various variables such as the camera and the environment, and therefore introduces some registration inaccuracies. Furthermore using homography may result in both jitter, caused by instability in homography, and latency, as the result of expensive detection and pose estimation calculations. To remove the effects caused by the homography and separate them from the graphics rendering, we introduced an alternative approach using projective geometry, based on Virtual Reality (VR) principles. Where we use 3D tracked data which can be provided by an external tracking system. We presented our prototype system to test and demonstrate the geometry-based UPR technique, where we confirmed the removal of homography inaccuracies such as jitters or latency. It is, however, worth mentioning that using an external tracking system adds some restrictions such as the tracking setup time and limited tracking range. Furthermore, we introduced a two-part semi-automatic, calibration technique to compensate for the misalignments between the tracking reference, the camera, and the screen, 
which estimates more accurate poses of the camera and the screen of the hand-held device.

Our geometry based UPR method was successful in reducing the mis-registration issue of the static device perspective rendering (DPR), however there are some misalignments, caused mostly by the displacement of the eye and the camera. We evaluated the geometry based UPR method in a formal user study, comparing it with DPR, for touch-based interaction with virtual objects, for both selection and pose manipulation. In these experiments the users performed the find and selection task significantly faster using DPR, however we could not find any significant difference between the compared perspectives for the pose manipulation test. Furthermore some of the test subjects expressed that the wider field of view of the DPR made it easier to find the objects for selection. Considering that the UPR's field of view is dynamically changed based on the distance between the screen and the user's view, it can mean that the subjects held the device in a position which led to a smaller field of view compared with the static field of view of the DPR in our study prototype system. On the contrary, a number of the test subjects believed that selection was easier and more intuitive with the user's perspective instead of the device's (camera's) perspective. This, we believe, is caused by the corrected perspective of UPR, where the virtual object is rendered, on the screen, inline with it's correspondence in the real world from the user's point of view.

For the pose manipulation of a virtual object we did not find any significant effect of using UPR. We believe the lack of significant effect may stem from a shortcoming in our test design, which did not force the users to also interact with the real world, therefore they were able to complete the manipulation task by mostly looking only through the screen. This, reduced the importance of alignment between the subject's view on the screen and, the real world, around it, which consequently reduced the benefit of using UPR. In general more test subjects, however, found UPR to be more natural and intuitive for pose manipulation of a virtual object.

\subsection{Device Pose-based Interaction}

In hand-held AR the device itself can be used, for direct 3D interaction with the virtual world, similar to using a wand in VR. This, for pose manipulation, is done by mapping the changes of the device pose to the pose of the manipulated object. Two existing device pose-based manipulation techniques are based on the AR which uses the device and the camera's perspective, which leads to different rotation issues. One of the techniques fixes an object to the device throughout the pose manipulation, which leads to moving the object while rotating it. This consequently makes it difficult to rotate an object without moving it, which is almost impossible for an object at a distance not reachable by the user. The other technique moves the object relative to the device during the pose manipulation, which loses sight of the virtual object during yaw and pitch rotations. This is a consequence of 
the device perspective used, where rotating the device also rotates the view. To remove these issues and create a better wand like experience for interaction using a hand-held device, we introduced two device pose-based manipulation techniques, developed based on the user perspective AR. With the first techniques, we took the relative movement approach, and thus the object mimics the movements of the device during the pose manipulation. We evaluated our first device pose-based technique and compared it with the existing ones in a user study, where subjects used these techniques to dock a virtual object at a target. For a near, reachable, object our technique significantly outperformed the DPR-based technique with the relative mapping, however we could not find any significant difference from the other technique, which fixes the object to the device. Looking only at the rotation part of the pose manipulation, our technique is faster than the other techniques, which indicates that our technique resolves the rotation issues with the compared ones. Also subjects expressed their preference towards our technique. Our technique also required less pose changes, to correct the view during the pose manipulation, which shows the effect of using the user's perspective.

Our first introduced device pose-based manipulation technique resolves the rotation issues with the existing DPR based techniques, however it has a translation issue, caused by different amounts of relative translation in perspective for distant objects, which prevents a continuous pose manipulation. We, therefore, introduced a second UPR based technique, which fixes the object to the user's view through a locking point on the screen and is capable of keeping the manipulated object continuously in the user's view throughout the pose manipulation. This technique significantly outperformed our previously introduced DM technique in a user study, where the subjects used these techniques to solve a virtual puzzle by putting the pieces in correct place. Furthermore, the result of this study indicated that the second technique required significantly less movement of the device, which also is confirmed by the technique being regarded by the subjects as less tiring. The second technique required less re-grabs of the objects to correct the perspective which shows a more continuous manipulation. Generally the results, we believe, stem from the corrected translation of the second technique compared to the previous one, which consequently makes it possible to keep the objects continuously in the view during the pose manipulation.

We also explored the benefits of the device pose-based interaction, for selecting a virtual object, compared to the common single-touch selection, such as reducing finger occlusion and fatigue. The existing device pose-based selection techniques either use a static position, such as the center of the screen, or a dynamic position near the center of the screen to select objects. We presented a slightly modified version of the existing device center-based selection which enables the selection of the nearest objects to the center of the screen and thus makes it easier to select multiple virtual objects with less movement of the device. We introduced another technique, which allows selection of multiple objects by their dynamically assigned 
icons, placed as a list by the edges of the screen. To evaluate the performance of our introduced selection techniques, we also compared them to single touch-selection in a user study. The results revealed that more subjects preferred selection techniques which use the center of the screen, and chose it as a more natural and intuitive technique. This technique was also significantly faster than our other, icon-based, technique however the mean time difference with Touch-select was not significant. The icon-based selection technique, however, required significantly less movement of the device compared to the other techniques, and was chosen by the subjects to be less tiring than the touch-based selection, although the subjects thought the center-based technique was less tiring than the icon-based. 




\section{Bibliography}

[1] SDL: Simple directmedia layer. http://http://www.libsdl.org/. [page 13]

[2] R. Azuma. A survey of augmented reality. Presence, 6(4):355-385, 1997. [page 2]

[3] M. Bajura, H. Fuchs, and R. Ohbuchi. Merging virtual objects with the real world: Seeing ultrasound imagery within the patient. SIGGRAPH Comput. Graph., 26(2):203-210, 1992. [page 2]

[4] M. Baldauf and P. Fröhlich. Snap target: Investigating an assistance technique for mobile magic lens interaction with large displays. International Journal of Human Computer Interaction, 30(6):446-458, 2014. [pages 28 and 29]

[5] D. Baricevic, C. Lee, M. Turk, T. Hollerer, and D. Bowman. A hand-held ar magic lens with user-perspective rendering. In Mixed and Augmented Reality (ISMAR), 2012 IEEE International Symposium on, pages 197-206, 2012. [page 36]

[6] S. Benhimane and E. Malis. Homography-based 2d visual tracking and servoing. The International Journal of Robotics Research, 26(7):661-676, 2007. [page 7]

[7] W. Birkfellner, M. Figl, K. Huber, F. Watzinger, F. Wanschitz, J. Hummel, R. Hanel, W. Greimel, P. Homolka, R. Ewers, and H. Bergmann. A headmounted operating binocular for augmented reality visualization in medicine design and initial evaluation. Medical Imaging, IEEE Transactions on, 21(8): 991-997, 2002. [page 2]

[8] D. A. Bowman and L. F. Hodges. Formalizing the design, evaluation, and application of interaction techniques for immersive virtual environments. Journal of Visual Languages 83 Computing, 10(1):37 - 53, 1999. [pages 1 and 3]

[9] D. A. Bowman, D. B. Johnson, and L. F. Hodges. Testbed evaluation of virtual environment interaction techniques. In Proceedings of the ACM Symposium on Virtual Reality Software and Technology, VRST '99, pages 26-33, New York, NY, USA, 1999. ACM. [page 33] 
[10] G. Bradski. opencv. Dr. Dobb's Journal of Software Tools, 2000. [page 13]

[11] P. Dell'Acqua, L. V. Klompstra, T. Jaarsma, and A. Samini. An assistive tool for monitoring physical activities in older adults. In 2013 IEEE 2nd International Conference on Serious Games and Applications for Health (SeGAH), pages 1-6, 2013.

[12] Y. Du, H. Ren, G. Pan, and S. Li. Tilt \& touch: Mobile phone for 3d interaction. In Proceedings of the 13th International Conference on Ubiquitous Computing, UbiComp '11, pages 485-486, New York, NY, USA, 2011. ACM. [page 23]

[13] S. Engelhardt, A. Langs, G. Lochmann, I. Schmidt, and S. Muller. Molearlert - an augmented reality game based on lemmings. In Mixed and Augmented Reality, 2009. ISMAR 2009. 8th IEEE International Symposium on, pages 183-184, 2009. [page 2]

[14] B. Furht, editor. Desktop Virtual Reality, pages 150-151. Springer US, Boston, MA, 2008. [page 8]

[15] M. Galvao and E. Zorzal. Augmented reality applied to health education. In Virtual and Augmented Reality (SVR), 2013 XV Symposium on, pages 268-271, 2013. [page 2]

[16] M. Hancock, T. ten Cate, and S. Carpendale. Sticky tools: Full 6dof force-based interaction for multi-touch tables. In Proceedings of the ACM International Conference on Interactive Tabletops and Surfaces, ITS '09, pages 133-140, New York, NY, USA, 2009. ACM. [page 4]

[17] R. Hartley and A. Zisserman. Multiple View Geometry in Computer Vision. Cambridge University Press, New York, NY, USA, 2 edition, 2003. [page 19]

[18] A. Henrysson, M. Billinghurst, and M. Ollila. Virtual object manipulation using a mobile phone. In Proceedings of the 2005 International Conference on Augmented Tele-existence, ICAT '05, pages 164-171, New York, NY, USA, 2005. ACM. [page 23]

[19] A. Hill, J. Schiefer, J. Wilson, B. Davidson, M. Gandy, and B. MacIntyre. Virtual transparency: Introducing parallax view into video see-through ar. 2013 IEEE International Symposium on Mixed and Augmented Reality (ISMAR), 0: 239-240, 2011. [page 7]

[20] O. Hilliges, D. Kim, S. Izadi, M. Weiss, and A. Wilson. Holodesk: Direct $3 \mathrm{~d}$ interactions with a situated see-through display. In Proceedings of the SIGCHI Conference on Human Factors in Computing Systems, CHI '12, pages 2421-2430, New York, NY, USA, 2012. ACM. [page 4] 
[21] J. D. Hincapie-Ramos, K. ozacar, P. Irani, and Y. Kitamura. Gyrowand: An approach to imu-based raycasting for augmented reality. 36:90-96, 2016. [page 4]

[22] L. C. Huey, P. Sebastian, and M. Drieberg. Augmented reality based indoor positioning navigation tool. In Open Systems (ICOS), 2011 IEEE Conference on, pages 256-260, 2011. [page 2]

[23] N. Katzakis and M. Hori. Mobile phones as 3-dof controllers: A comparative study. In Dependable, Autonomic and Secure Computing, 2009. DASC '09. Eighth IEEE International Conference on, pages 345-349, 2009. [page 23]

[24] K. Kirchbach and C. Runde. Augmented reality for construction control. In Information Visualisation (IV), 2012 16th International Conference on, pages 440-444, 2012. [page 2]

[25] Y. Li. Augmented reality for remote education. In Advanced Computer Theory and Engineering (ICACTE), 2010 3rd International Conference on, volume 3, pages V3-187-V3-191, 2010. [page 2]

[26] R.-h. Liang and J.-f. Mao. Hand-eye calibration with a new linear decomposition algorithm. Journal of Zhejiang University SCIENCE A, 9(10):1363-1368, 2008. [page 18]

[27] A. Martinet, G. Casiez, and L. Grisoni. Integrality and separability of multitouch interaction techniques in 3d manipulation tasks. IEEE Transactions on Visualization and Computer Graphics, 18(3):369-380, 2012. [page 4]

[28] P. Milgram and F. Kishino. A taxonomy of mixed reality visual display. IEICE Trans. Inf. ES Sys., D, 77(12):1321-1329, 1994. [page 1]

[29] O. Mohareri and A. Rad. Autonomous humanoid robot navigation using augmented reality technique. In Mechatronics (ICM), 2011 IEEE International Conference on, pages 463-468, 2011. [page 2]

[30] A. Mossel, B. Venditti, and H. Kaufmann. 3dtouch and homer-s: Intuitive manipulation techniques for one-handed handheld augmented reality. In Proceedings of the Virtual Reality International Conference: Laval Virtual, VRIC '13, pages 12:1-12:10, New York, NY, USA, 2013. ACM. [page 24]

[31] J. Nielsen. Noncommand user interfaces. Commun. ACM, 36(4):83-99, 1993. [page 1]

[32] S. J. D. Prince, K. Xu, and A. D. Cheok. Augmented reality camera tracking with homographies. IEEE Computer Graphics and Applications, 22(6):39-45, 2002. [page 7] 
[33] G. Robertson, M. Czerwinski, and M. van Dantzich. Immersion in desktop virtual reality. In Proceedings of the 10th Annual ACM Symposium on User Interface Software and Technology, UIST '97, pages 11-19, New York, NY, USA, 1997. ACM. [page 8]

[34] M. Roccetti, G. Marfia, A. Amoroso, S. Caraceni, and A. Varni. Augmenting augmented reality with pairwise interactions: The case of count luigi ferdinando marsili shooting game. In Consumer Communications and Networking Conference (CCNC), 2012 IEEE, pages 467-471, 2012. [page 2]

[35] A. Samini and K. Lundin Palmerius. A perspective geometry approach to user-perspective rendering in hand-held video see-through augmented reality. In Proceedings of the 20th ACM Symposium on Virtual Reality Software and Technology, VRST '14, pages 207-208, New York, NY, USA, 2014. ACM.

[36] A. Samini and K. Lundin Palmerius. Device registration for 3d geometry-based user-perspective rendering in hand-held video see-through augmented reality. In L. T. De Paolis and A. Mongelli, editors, Augmented and Virtual Reality, volume 9254 of Lecture Notes in Computer Science, pages 151-167. Springer International Publishing, 2015.

[37] A. Samini and K. Lundin Palmerius. A study on improving close and distant device movement pose manipulation for hand-held augmented reality. In Proceedings of the 22Nd ACM Conference on Virtual Reality Software and Technology, VRST '16, pages 121-128, New York, NY, USA, 2016. ACM.

[38] A. Samini and K. Lundin Palmerius. A User Study on Touch Interaction for User-Perspective Rendering in Hand-Held Video See-Through Augmented Reality, pages 304-317. Springer International Publishing, Cham, 2016.

[39] A. Samini and K. Lundin Palmerius. Towards the ultimate hand-held augmented reality interaction $\mid$ a study on selection and pose manipulation techniques. 2017.

[40] A. Samini and K. L. Palmerius. Popular performance metrics for evaluation of interaction in virtual and augmented reality. In 2017 International Conference on Cyberworlds (CW), volume 00, pages 206-209, 2017.

[41] M. Sasakura, A. Kotaki, and J. Inada. A 3d molecular visualization system with mobile devices. In 2011 15th International Conference on Information Visualisation, pages 429-433, 2011. [pages 23 and 24]

[42] Y. Sato, M. Nakamoto, Y. Tamaki, T. Sasama, I. Sakita, Y. Nakajima, M. Monden, and S. Tamura. Image guidance of breast cancer surgery using 3-d ultrasound images and augmented reality visualization. Medical Imaging, IEEE Transactions on, 17(5):681-693, 1998. [page 2] 
[43] M. Shah, R. D. Eastman, and T. Hong. An overview of robot-sensor calibration methods for evaluation of perception systems. In Proceedings of the Workshop on Performance Metrics for Intelligent Systems, PerMIS '12, pages 15-20, New York, NY, USA, 2012. ACM. [page 18]

[44] Y. C. Shiu and S. Ahmad. Calibration of wrist-mounted robotic sensors by solving homogeneous transform equations of the form $\mathrm{ax}=\mathrm{xb}$. Robotics and Automation, IEEE Transactions on, 5(1):16-29, 1989. [page 18]

[45] D. Shreiner and T. K. O. A. W. Group. OpenGL Programming Guide: The Official Guide to Learning OpenGL, Versions 3.0 and 3.1. Addison-Wesley Professional, 7th edition, 2009. [pages 9 and 13]

[46] I. E. Sutherland. A head-mounted three dimensional display. In Proceedings of the December 9-11, 1968, Fall Joint Computer Conference, Part I, AFIPS '68 (Fall, part I), pages 757-764, New York, NY, USA, 1968. ACM. [page 2]

[47] T. Tanikawa, H. Uzuka, T. Narumi, and M. Hirose. Integrated view-input interaction method for mobile ar. In 3D User Interfaces (3DUI), 2015 IEEE Symposium on, pages 187-188, 2015. [pages 24 and 28]

[48] M. Tomioka, S. Ikeda, and K. Sato. Approximated user-perspective rendering in tablet-based augmented reality. In Mixed and Augmented Reality (ISMAR), 2013 IEEE International Symposium on, pages 21-28, 2013. [page 7]

[49] D. Wagner and I. Barakonyi. Augmented reality kanji learning. In Proceedings of the 2Nd IEEE/ACM International Symposium on Mixed and Augmented Reality, ISMAR '03, pages 335-, Washington, DC, USA, 2003. IEEE Computer Society. [page 2]

[50] C. Ware, K. Arthur, and K. S. Booth. Fish tank virtual reality. In Proceedings of the INTERACT' '93 and CHI'93 Conference on Human Factors in Computing Systems, CHI '93, pages 37-42, New York, NY, USA, 1993. ACM. [page 8]

[51] F. Zhou, H. B.-L. Duh, and M. Billinghurst. Trends in augmented reality tracking, interaction and display: A review of ten years of ismar. In Proceedings of the rth IEEE/ACM International Symposium on Mixed and Augmented Reality, ISMAR '08, pages 193-202, Washington, DC, USA, 2008. IEEE Computer Society. [page 3]

[52] H. Zhuang and Z. S. Roth. Camera Aided Robot Calibration. CRC Press, Inc., Boca Raton, FL, USA, 1995. [page 18] 

Appended Papers 



\section{Publications}

The publications associated with this thesis have been removed for copyright reasons. For more details about these see:

http://urn.kb.se/resolve?urn=urn:nbn:se:liu:diva-148005 